Z. Epileptol. $2022 \cdot 35: 56-72$

https://doi.org/10.1007/s10309-022-00469-w

Accepted: 17 January 2022

Published online: 8 February 2022

(c) The Author(s) 2022

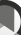

\section{Generalized absence seizures: Where do we stand today?}

\author{
Hermann Stefan ${ }^{1}$ Eugen Trinka ${ }^{2,3,4,5}$ \\ 'Department of Neurology—Biomagnetism, University Hospital Erlangen, Erlangen, Germany \\ ${ }^{2}$ Department of Neurology, Christian Doppler University Hospital, Center for Cognitive Neuroscience, \\ Paracelsus Medical University, Salzburg, Austria \\ ${ }^{3}$ Neuroscience Institute, Christian Doppler University Hospital, Center for Cognitive Neuroscience, \\ Paracelsus Medical University, Salzburg, Austria \\ ${ }^{4}$ Department of Public Health, Health Services Research and Health Technology Assessment, \\ UMIT_-University for Health Sciences, Medical Informatics and Technology, Hall in Tirol, Austria \\ ${ }^{5}$ Karl Landsteiner Institute for Neurorehabilitation and Space Neurology, Salzburg, Austria
}

\title{
Abstract
}

Generalized absence seizures are discussed here with respect to changing scientific concepts and newer findings, challenging the strict dichotomy of "generalized" vs. "focal" which may be counterproductive to the development of new ideas and treatments. Data from semiology, structural, and functional studies using quantitative electroencephalography (EEG), video-EEG monitoring, magnetoencephalography, magnetic resonance imaging, and positron emission tomography as well as neuropathology suggest a nosological spectrum from focal to generalized seizuregenerating mechanisms. The terms "focal" and "generalized" as used to describe seizures represent abstractions and idealizations rather than ontological entities. The new terminology and classification of the ILAE (2017), despite its enormous merits, unfortunately also facilitates and fosters reductionist thinking, which may be pragmatic from a utilitarian perspective, but risks hindering scientific developments for the future. For instance, the seizure semiology of absences as a paradigmatic generalized seizure type is now classified as "non-motor seizure." A detailed phenomenological analysis reveals that motor activity is an integral part of this seizure type. Many motor and socalled automatic absence symptoms can be understood as correlated elements of a general organization plan of the cortex. Corresponding functional and structural changes seen in imaging and high-resolution electrophysiology studies indicate focal contributions to seizure generation and a combination of focal and generalized features. Functional findings indicate that the frontal lobe with its projections to other brain areas may play an important role in generalized absence seizures. In this critical review we assess the evolution of pathophysiological concepts through the ages and present new research approaches for diagnosis and treatment.

\section{Keywords}

Video-EEG · Frontal lobe · Gestalt · Pathophysiology · Treatment

\section{Classification of generalized seizures}

\section{From early descriptions to present} times

In 1772, Tissot distinguished seizures from epilepsies, and later Esquirol [1] differentiated between petit mal and grand mal seizures.
Absences are an important hallmark of many generalized epilepsy syndromes and can be easily investigated by simple observation alone, and since the late 20th century with video-electroencephalographic (EEG) monitoring. Detailed analyses of their semiology and EEG characteristics have been published. Absence seizures were first described in detail by Poupart [2]. Calmeil [3] introduced the term "absence." Herpin [4] reported the case of 
a 13-year-old boy with bilateral myoclonic jerks-a seizure type later assigned to juvenile myoclonic epilepsy (JME) —and observed that bilateral myoclonic seizures can present in combination with bilateral tonic-clonic seizures (grand mal seizures). A detailed history of absences and generalized epilepsies is given elsewhere $[5,6]$. The International League Against Epilepsy (ILAE) characterized epileptic seizures, epilepsies, and syndromes in 1970 and 1989. Seizures of idiopathic "generalized" epilepsies include absences, tonic-clonic, and bilateral myoclonic events (ILAE Commission on Classification [7, 8]). These seizure types are the key features of particular epilepsy syndromes such as childhood (CAE) or juvenile absence epilepsy (JAE), and juvenile myoclonic epilepsy (JME).

\section{I) Absences are an important hallmark of many generalized epilepsy syndromes}

In 1981, the ILAE defined absence seizures as impairment of consciousness with mild clonic, atonic, tonic, or autonomic components. In the latest ILAE Classification [9], generalized absence seizures are defined as "generalized non-motor seizures," which fails to take the full spectrum of clinical phenomena into consideration [10].

\section{Abbreviations}

\begin{tabular}{ll} 
ADHD & $\begin{array}{l}\text { Attention deficit hyperactivity } \\
\text { disorder }\end{array}$ \\
ASM & Anti-seizure medication \\
CAE & Childhood absence epilepsy \\
CIN & Cortical initiation network \\
FEF & frontal eye field \\
fMRI & Functional MRI \\
IGE & Idiopathic generalized epilepsy \\
& (now called "genetic generalized \\
& epilepsy") \\
JAE & Juvenile absence epilepsy \\
JMEA & Juvenile myoclonic epilepsy with \\
& absences \\
MAE & Myoclonic absence epilepsy \\
MEG & Magnetoencephalography \\
MRI & Magnetic resonance tomography \\
PET & Positron emission tomography \\
SEEG & Stereo-electroencephalography \\
SPECT & Single-photon emission tomography \\
$V P A$ & Valproate \\
VNS & Vagus nerve stimulation \\
Video-EEG & Simultaneous recording of video \\
& and EEG \\
\hline
\end{tabular}

Electroclinical correlates of generalized seizures

Rosenthal [11] already mentioned that accessory motor signs may be present during absences. For a while after the identification of spike-wave paroxysms in EEG, phenomenological seizure analysis was dominated by electrographic research. Absences with $3 / \mathrm{s}$ spike-waves were defined as "typical." Later, Janz [12] referred to absences without eye or lid movements as "simple." According to Gastaut et al. [13], lid elevations are tonic ocular seizure signs. Janz [12] described tonic eyelid movements as corresponding to "retropulsive" absences and further differentiated between "adversive" and "propulsive" absences.

The systematic objective description of absences using video-EEG monitoring started with Penry et al. [14]. In addition to the brief suspense of consciousness as a hallmark of this seizure, they saw frequent motor phenomena, such as myocloni and automatisms. In a prospective video-polygraphic study using computersupported documentation, 528 absences from 59 patients were analyzed $[15,16]$. In addition to EEG lid-actogram, EMG (Electromyography), ECG, respiration, and skin resistance was recorded. The video analysis was conducted first with normal speed and subsequently with slow-motion replay. Overall, $62 \%$ of the patients had myoclonic symptoms, 37\% had automatisms, $42 \%$ tonic, and $23 \%$ autonomic ictal signs [16]. All patients were recorded in a standardized sitting position wearing a shortsleeved shirt and shorts without shoes and socks; a total view of the body and a closeup view of the face could be obtained. The body distribution of ictal myoclonic and tonic signs is shown in 0 Fig. 1a. Absence "subtypes" related to motoric activity were dominated by lid motoric activity in $23 \%$ of all patients, retropulsive movements in $23 \%$, oral in $6 \%$, and versive in $4 \%$. In the other patients none of these signs dominated, and simple absences were observed only in $2 \%$ of all patients. Thus, the presence of motor phenomena during absences is the rule and not the exception $[10,16]$. Aside from the main semiological traits, some variability has also been reported.
A special dynamic of different accessory ictal signs during the absence was detected (- Fig. 1b). Single elements of the whole motor program of absence seizures occurred in some other absences of the same patient, time-fixed as a fragment of the total motoric semiology sequence ([18]; - Fig. 1c). For instance, absence 1 of - Fig. 1c initially demonstrates elevating of the eyelids and looking to the left, later followed by chewing and then movements of the left hand. In absence 2, initially only the ocular signs occurred, later followed by chewing at the same time interval after spike-wave onset as in absence 1 . In absence 4 of the same patient, elevation of the lids was followed later during the seizure by stretching of the left hand, also at the same time intervals as in absence 1. The time-fixed appearance of ocular, oral, and extremity movements is clearly visible in absence 1, whereas in other absences only "tips of the iceberg" are visible. When the waxing and waning epileptogenicity level during an absence in the eloquent area is strong enough, then the ictal focal sign occurs at that time.

The overall Gestalt of the accessory ictal signs showed a "cranio-caudal march" (- Fig. 1d). This means that regardless of the differentiation in myoclonic, tonic, or automatic stereotyped labels, activation of motoric events was time-linked from cranial to caudal body parts (often the legs earlier than the arms). In addition, focal features such as a spike focus at the onset of an absence with bilateral spike-wave were observed (- Fig. 2).

The time of occurrence of the semiological ictal elements had a constant latency relative to EEG ictal onset ( $\bullet$ Fig. 1c) as reported by Stefan et al. [18]. The duration of spike-wave paroxysm was associated with an increasing number of ictal signs. Initial ocular signs being followed by oral signs (mouth opening) is also seen in primary tonic-clonic seizures in other idiopathic generalized epilepsies (IGEs; [17]). Many motor as well as so-called automatic absence symptoms can be understood as correlated elements of a cortical organization plan.

Similar findings have been reported in later studies: Shylaja et al. [19] studied absence seizures in children with simultaneous video-EEG and transverse topo- 
Body distribution of motoric absence signs

Body region

Ocular (lid/bulb)

myoclonic

tonic

Face

$57.5 \%$

$46.9 \%$

Head

$17.0 \%$

$12.0 \%$

Arm

$13.4 \%$

$12.6 \%$

Arm

\section{$6.8 \%$}

$8.4 \%$

Leg

$4.0 \%$

$17.5 \%$

Trunk

$1.3 \%$

$2.6 \%$

a

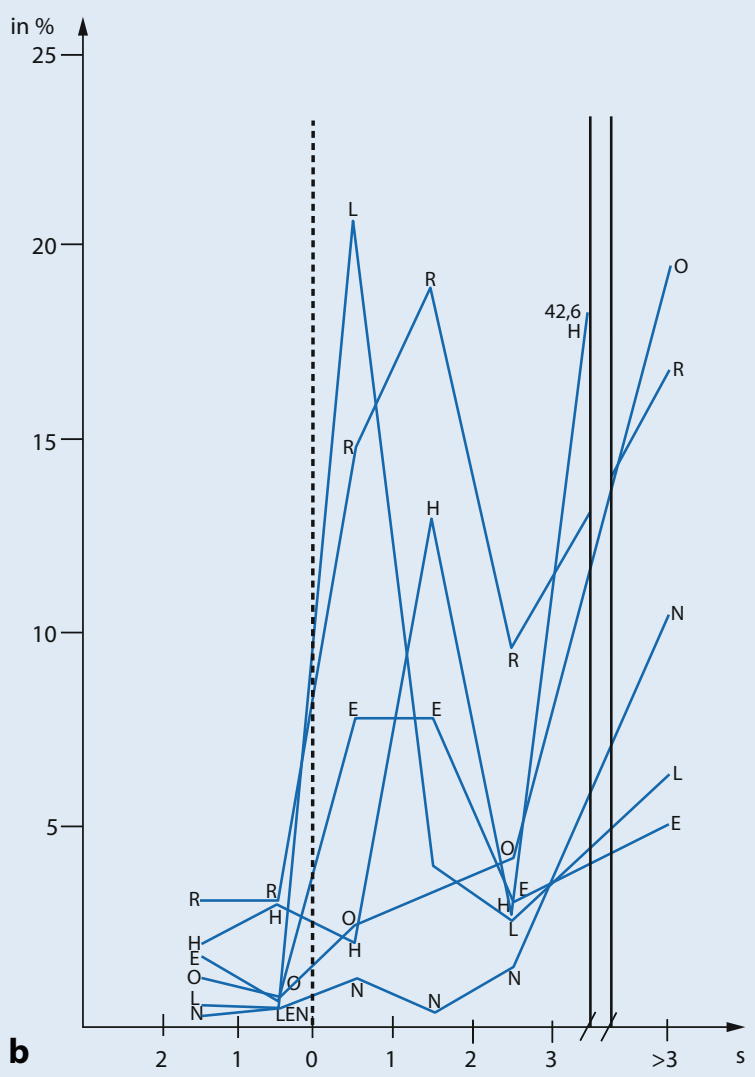

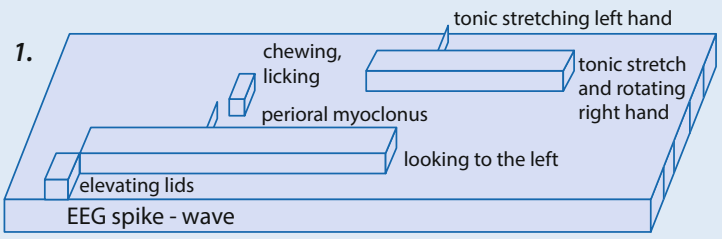
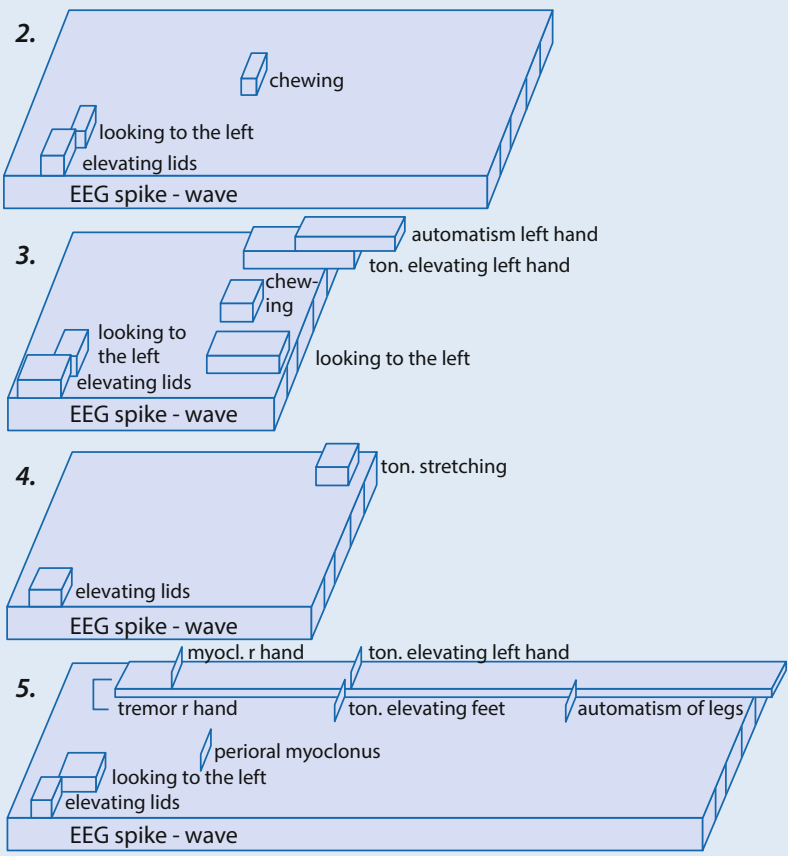

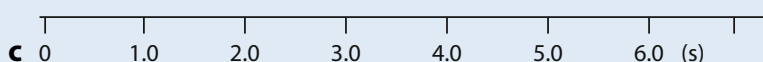

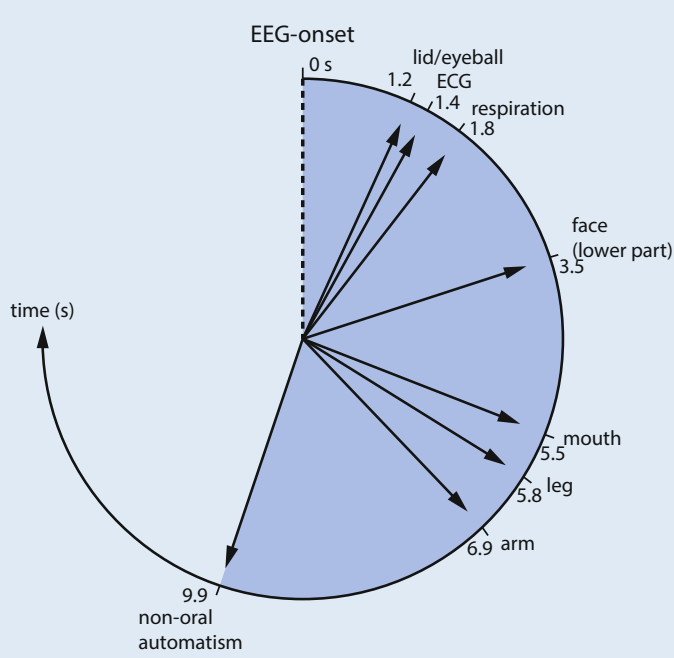

Fig. $1 \Delta$ a Body distribution of motoric ictal events during absences. In patients with five or more recorded seizures, certain motoric signs in more than $50 \%$ of absences of a patient dominated the ictal semiology. In this "absence subtypes" lidmotoric activity dominated in $23.4 \%$ of all patients, retropulsive movements in $23 \%$, oral in $6.3 \%$, and versive in $4.2 \%$. In the other patients none of these signs dominated, simple absences were most frequent only in $2.4 \%$ [16]. b Time-related activity peaks during absence seizures: $(0)$ shows spike-wave onset of absence. Respiration $(R)$, skin galvanic reflex $(H)$, ECG $(E)$, oral automatism $(O)$, non-oral automatisms $(N)$, rhythmic and/or tonic eye movement $(L)$. The events occur predominantly early in the absence, sometimes before spike-wave onset; automatisms occur later [16].c Constancy and variability of ictal motor signs in relation to time: The figure shows ictal motor activity in five absences in one patient: (1) complex movement pattern during the first absence; (2) identical ictal signs, but only isolated as single element in other absences or combination of few elements like fragments of the whole complex movement pattern of seizure 1; (3) constant latency to seizure onset. In some absences, elements of the motor program are only visible like the tip of an iceberg. This fact is an important precondition for unraveling connections in order to understand the neurobiological context of discrete ictal absence manifestations [16]. d "Gestalt" of temporal dynamics of absence structure [17] (b: ๑) Thieme Verlag; c: @ Elsevier; d: @ Wolters Kluwer; mit freundlicher Genehmigung) 


\begin{tabular}{|c|c|c|c|c|}
\hline Time & Absence 1 & Absence 2 & Absence 3 & Absence 4 \\
\hline Ictal sign occurrence & eyes open & eyes closed & eyes closed & eyes closed \\
\hline \multicolumn{5}{|l|}{ in seconds } \\
\hline \multirow[t]{2}{*}{1} & lid rhythmic & lid rhythmic & eye tonic & eye tonic \\
\hline & $\begin{array}{l}\text { (lid accelerometer) } \\
\text { respiration stop }\end{array}$ & $\begin{array}{l}\text { head nodding } \\
\text { mouth }\end{array}$ & $\begin{array}{l}\text { opening } \\
\text { head nodding }\end{array}$ & opening \\
\hline 2 & & & eye to the right & eye to the right \\
\hline \multirow[t]{2}{*}{3} & no reaction & & & \\
\hline & eyes to right & $\begin{array}{l}\text { left hand } \\
\text { clenched wrist }\end{array}$ & & \\
\hline 5 & thead nodding & 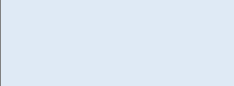 & end absence & $\begin{array}{l}\text { elevation left hand } \\
\text { clenching left wrist }\end{array}$ \\
\hline 6 & & & & Babinski left \\
\hline 7 & $\begin{array}{l}\text { rhythmic thumb } \\
\text { movements left }\end{array}$ & end absence & & \\
\hline 8 & $\begin{array}{l}\text { then legs } \\
\text { oral automatism }\end{array}$ & & & end absence \\
\hline \multirow[t]{2}{*}{9} & & & & \\
\hline & end absence & & & \\
\hline 10 & $\begin{array}{l}\text { EEG spike precentral, then } \\
\text { generalized } 3 \mathrm{~s} / \mathrm{W}\end{array}$ & $\begin{array}{l}\text { EEG spike precentral, then } \\
\text { generalized } 3 / \mathrm{s} \text { SW }\end{array}$ & $\begin{array}{l}\text { irregular SW, then regular } \\
3 / \mathrm{s} \text { SW }\end{array}$ & $\begin{array}{l}\text { irregular SW, then regular } 3 / \mathrm{s} S W \\
\text { respiration stops and pulse period } \\
\text { variability decreases before absence }\end{array}$ \\
\hline
\end{tabular}

Fig. $2 \triangleleft$ Summary of ictal findings for four absences in one patient with focal or bilateral spike-wave onset: Initial ocular phenomena vary as rhythmic lid or tonic movements, predominantly with versive eye movements. In absence 4, focal semiology starts with versive eye movement to the right, then tonic movement of the left arm followed by a Babinski phenomenon of the left toe. EEG focal and bilateral widespread 3/s spike-wave. Pulse period variability decreases $6 \mathrm{~s}$ before the spike-wave in absence 4. Summarized figure based on data from the study by H. Stefan [16]

graphical analyses and confirmed a succession of motor symptoms in absence seizures. Further results from a video-EEG analysis of absences were published by Sadleir et al. [20]. It was reported that 18 of 47 untreated patients had absences with duration shorter than $4 \mathrm{~s}$. The average seizure duration was $9.4 \mathrm{~s}$ and clinical features consisted of arrest of activity, loss of awareness, staring, and $3 /$ s eyelid movements, but there was individual variation.

In a comparative video-EEG study of typical absence seizures in 20 patients with IGE, 224 absences were analyzed [21]. The seizure semiology of $C A E, J A E$, juvenile myoclonic epilepsy with absences (JMEA), and myoclonic absence epilepsy (MAE) and their EEG correlates differed substantially: CAE showed more severe impairment of consciousness than JAE while the ictal manifestations in JMEA were often mild.

\section{I) Automatisms are rare in juvenile myoclonic epilepsy with absences}

Automatisms are rare in JMEA but frequent in CAE and JAE. Early eye-opening semiology was not observed in JMEA. The ictal EEG discharge was longer in JAE (mean $16.3 \pm 7.1 \mathrm{~s})$ than in CAE $(12.4 \pm 2.1 \mathrm{~s})$.
Japaridze [22] provided a synopsis from the literature on focal EEG features in IGE, which were observed in $70.2 \%$ of 118 patients. Seveniratne et al. [23] described 135 patients with IGE of whom 51.9\% had focal semiological signs (tonic-clonic seizures in $39.5 \%$, juvenile absences in $62.5 \%$, JME in $60 \%$ ). An overview of focal EEG abnormalities and focal ictal semiology in generalized epilepsy was provided by Fernandez-Baca Vaca et al. [24].

\section{Supplementary investigations: structural-functional studies}

Subtle MRI changes of the frontal lobe were reported by Woermann et al. [25], who investigated 20 patients with JME, 10 patients each with CAE and JAE, five patients with tonic-clonic seizures on awakening (TCSA), and 30 controls. Voxel-based morphometry detected volume reduction or increase in predominantly frontal and thalamic cortical areas [23]. Kim et al. [26] found that compared with control subjects, patients with CAE had smaller total and regional volumes of cortical gray matter in the right rostral middle frontal, right lateral orbitofrontal, and left rostral middle frontal regions, as well as in the right precentral, right superior, middle, left middle, and inferior temporal gyri. These structural changes were interpreted as the structural neuronal basis of absence seizures and neuropsychiatric comorbidities in CAE.

Magnetic resonance spectroscopy also showed changes in the thalamus and frontal or fronto-parieto-temporal-cingula-insular regions [27]. Interictal hypometabolism was found in frontal regions by Kapucu et al. [28]. Brain network mechanisms underlying generalized spike and wave discharges in human IGE has been investigated in several functional MRI studies in patients with IGE. They demonstrate that the thalamus, default mode areas, and caudate nuclei are involved during generalized spike-wave paroxysms and absence seizures. The highly synchronized activity in the thalamocortical network showed BOLD activation in the thalamus, the frontomesial cortex, and the cerebellum, and BOLD deactivation in default mode areas. For an overview of imaging studies see Moeller et al. [29] and Seveniratne et al. [23].

In addition to imaging of structural changes in epilepsy, the potential relevance of microdysgenesis has also been discussed [30]. Neuropathological examinations of eight patients with IGE syndromes found microdysgenesis with vary- 
The Electroencephalogram in Parasagittal Lesions

Kenan Tükel, M.D. and Herbert Jasper, M.D.

Department of Neurology and Neurosurgery of McGill University and the Montreal Neurological Institute
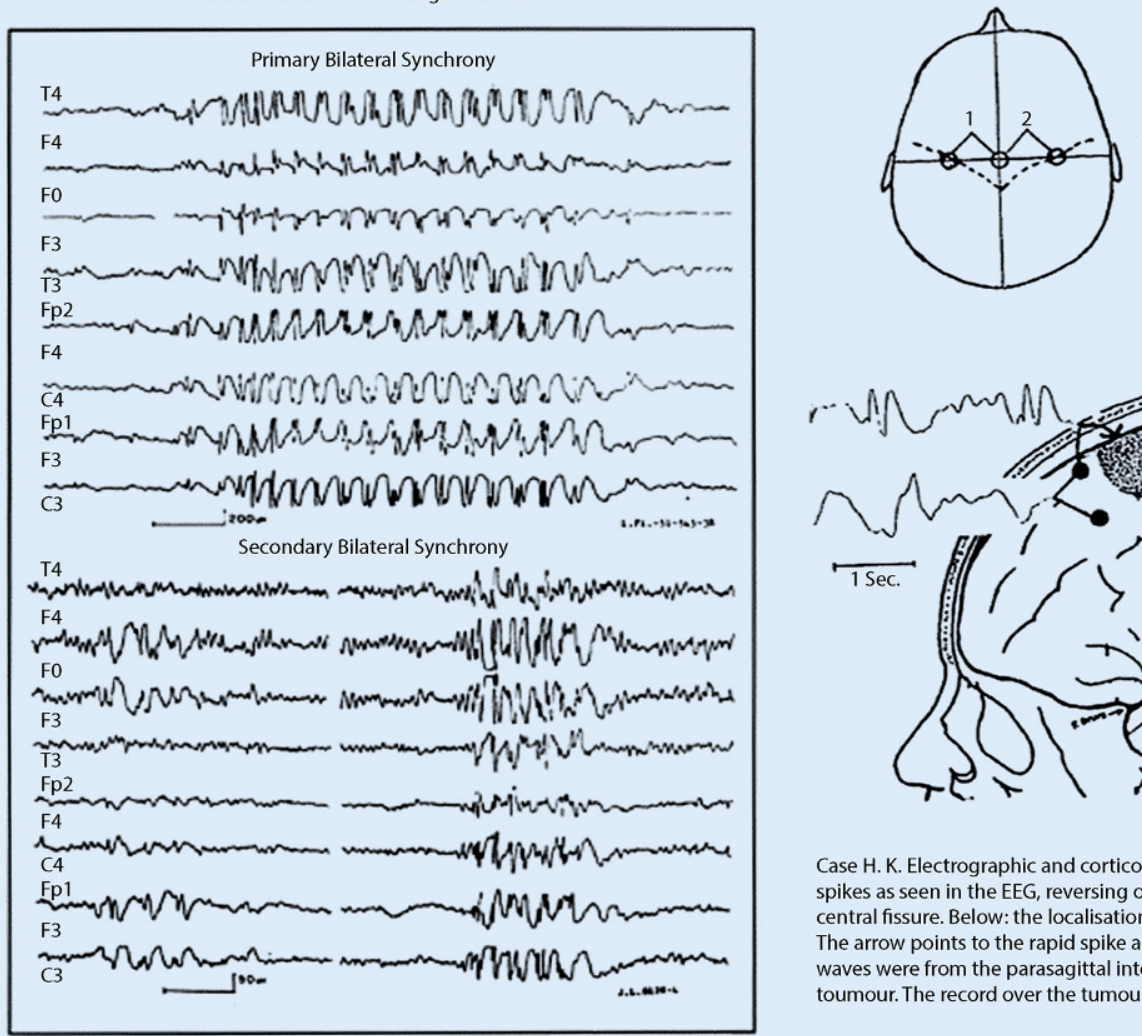

Preop.

H.K.5867

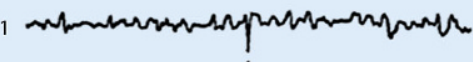

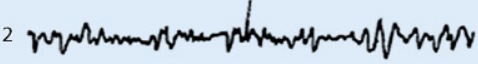
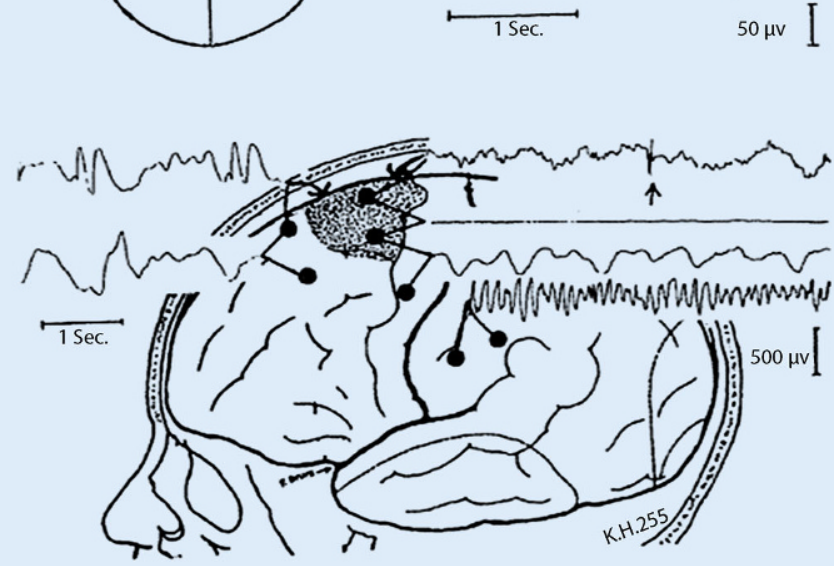

Case H. K. Electrographic and corticographic studies of parasagittal tumor. Above rapid spikes as seen in the EEG, reversing over central vertex. The broken lines represent the central fissure. Below: the localisation of the tumour is represented by the dotted area. The arrow points to the rapid spike activity as observed in the cortical electrogram. Delta waves were from the parasagittal intermediate frontal region around the borders of the toumour. The record over the tumour itself was silent.

Fig. $3 \Delta$ Electroencephalogram in parasagittal lesions. (From [37]) (@ John Wiley and Sons; mit freundlicher Genehmigung)

ing regional distribution seven cases [31, 32]. However, a comparison with autoptic investigations showed no statistical difference to a control collective [33], although the specimens were taken from different brain regions.

\section{Concepts of generalized seizures through the ages}

Jackson [34] held the following view:

"The facts that those very epilepsies in which consciousness is first lost, or is lost very early, are the cases in which the convulsion is nearly universal, in which the two sides are more nearly equally convulsed; and that it is in these cases that there is at the very first much pallor of the face, tend to confirm the conclusion that the sensori-motor processes concerned in consciousness are evolved out of and potentially contain all other (lower) series. It is, indeed, most significant, whatever the explanation may be, that there are slight cases (petit mal) in which, with transient loss of consciousness, there is deep pallor of the face (and body?) and a slight wave of universal movement."

With this notion of nearly, he emphasized that even in generalized convulsions there was a focal onset followed by "very rapid spread." It is rather extraordinary that he also included "slight cases" or petit mal in the same category of "universal convulsions."

Penfield and Jasper from the Montreal Neurological Institute developed a new theory of seizure generation in generalized epilepsy, and coined the term "centrencephalic system." It now seems that this concept was deeply inspired by the discovery of the role of the ascending reticular system in cortical EEG activation by Moruzzi and Magoun [35]. H. Jasper [36] concluded from observations in the cat that the diffuse thalamocortical pro- jection system, which we have called the "thalamic reticular system," has a very widespread and profound effect on behavior as a whole and may be involved in the mechanism of petit mal and generalized convulsive seizures as seen in humans. He wrote: "... in parallel with the experimental demonstration of the functional importance of the ascending reticular activating system and of its reciprocal interactions with the cortex, Penfield had developed the 'centrencephalic system' on the basis of his surgical experience."

However, it was Jasper himself who, together with Tükel, challenged this "brainstem concept" in 1952 by analyzing the EEG of 31 patients with various cortical parasagittal lesions [37]. The most prominent EEG pattern was bilateral synchronous spike-wave discharges, found in 26 of the 31 patients (- Fig. 3). To still support the "centrencephalic" theory of bilateral synchronous spike-wave activ- 

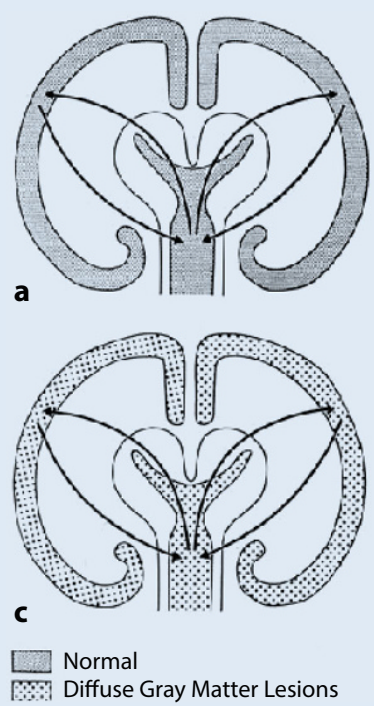

b
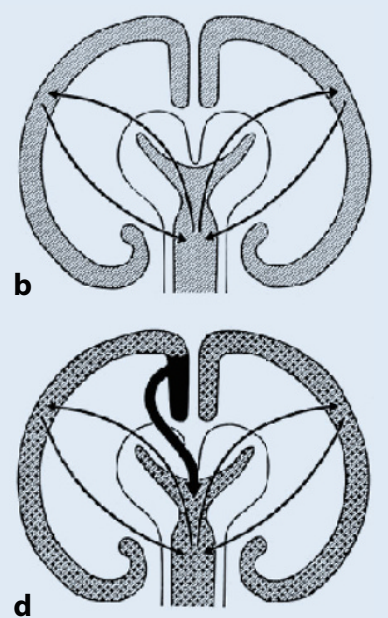

$\square$ Genetic

Gross Cortical Lesion

(1) Genetic ("classical") form

(2) Metabolic forms

(3) Organic forms

(a) without focal cortical lesion

(b) with focal cortical lesions

("secondary paroxysmal bilatera

synchronies") no known pathology

cortical and subcortical grey matter

lesions associated with systemic metabolic

disorders (renal failure, hypoglycemia,

hypocalcemia).

diffuse encephalopathies affecting cortica

and subcortical grey matter.

focal cortical lesions (often frontal

parasagittal). no gross lesions or diffuse discrete
Fig. $4<$ Generalized corticoreticular epilepsies. Some considerations on the pathophysiology of generalized bilaterally synchronous spike and wave discharge. (From [38]) (@) Elsevier, mit freundlicher Genehmigung) ity, they gave the ad hoc hypothesis of a secondary bilateral synchrony, whereby a "cortical focus can fire into subcortical structures and set off a projected secondary bilateral synchrony" and opposed this to the primary bilateral synchrony, found in true "centrencephalic epilepsy."

Gloor [38, 39] unified the cortical and the subcortical theories by developing the concept of "corticoreticular epilepsies" (• Fig. 4). He interpreted his experimental studies in cats on the pathophysiology of generalized bilateral synchronous spike and wave discharges as follows: "If the experimental studies in animals ... are considered as strongly in favour of the centrencephalic hypothesis, pharmacological studies, especially those employing the intracarotid injection of Metrazol and Sodium Amytal, are those militating against it, tending to support instead the alternative notion of a cortical origin of centrencephalic epilepsy." Furthermore, Niedermeyer [40] observed shifting focal accentuation of spike-wave complexes, but no constant focus during depth recordings. The author stated:
“... Our observations failed to provide any evidence of a primary thalamic focus," again emphasizing the cortical origin.

Are the dichotomies focal vs. generalized and cortical vs. subcortical seizure generators still valid in modern epileptology?

Lüders et al. [41] challenged the concepts of generalized versus focal epilepsies and idiopathic versus symptomatic epilepsies and asked whether these dichotomies are still valid in modern epileptology. What are the facts that support this view?

\section{I) The first step in seizure development may be of polygenetic origin}

According to Gloor [39], a bilateral synchronous spike-wave activity is indicative of an abnormal reaction of cortical neurons as result of thalamocortical discharges that are physiologically also involved in the triggering of sleep-spindles. This reaction with spike-wave activity as an EEG cor- relate corresponds to a diffuse and often mild cortical hyperexcitability. It can be interpreted as the first step on the way to an electro-clinically defined seizure. The more intensive second step of seizure development, or ictogenesis, is based on paroxysmal depolarization. Both mechanisms coexist in the brains of patients with IGEs and related conditions. The first step in seizure development may be of polygenetic origin. In a given brain region, the second step may predominate. In this way, electroclinical manifestations with generalized changes can be focally accentuated. In this concept, focal and generalized network activities are interacting not in isolation, but rather belong together.

Based on behavioral electrophysiological and imaging and other functional studies, Blumenfeld et al. [42] suggest that absence seizures impair focal rather than generalized brain functions. The authors postulate that a basic ictogenic tendency (most likely polygenetic) is accompanied by triggering or causative factors. Because these exist on a continuum, some patients' symptoms are in gray zone between focal and generalized epileptic activity. Nevertheless, Lüders and colleagues found it is useful to maintain the distinction for practical purposes, even if it is somewhat artificial [41]. In addition to a general genetic disposition, regional cortical networks, for instance, the motoric system functions, are involved, as suggested by several semiological-electrophysiological and imaging findings, which showed regionality in absence seizure manifestations. This means that there is in some way a temporary enhanced amalgamation of widespread excitability and cognitive as well as motor system activation. Focal or regional characteristics, therefore, are integral to generalized seizures in IGE.

Koutroumanidis et al. [43] suggested that in CAE focal EEG paroxysms reflect a system of multifocal nonlocalizing electrically unstable cortex in frontal and other regions. Anterior focal findings strongly suggest that the frontal lobe is important for the generation of $3-\mathrm{Hz}$ corticothalamic oscillations. Although these observations advance our understanding of the role of the frontal lobe in corticothalamic epileptogenesis, knowledge concerning the con- 


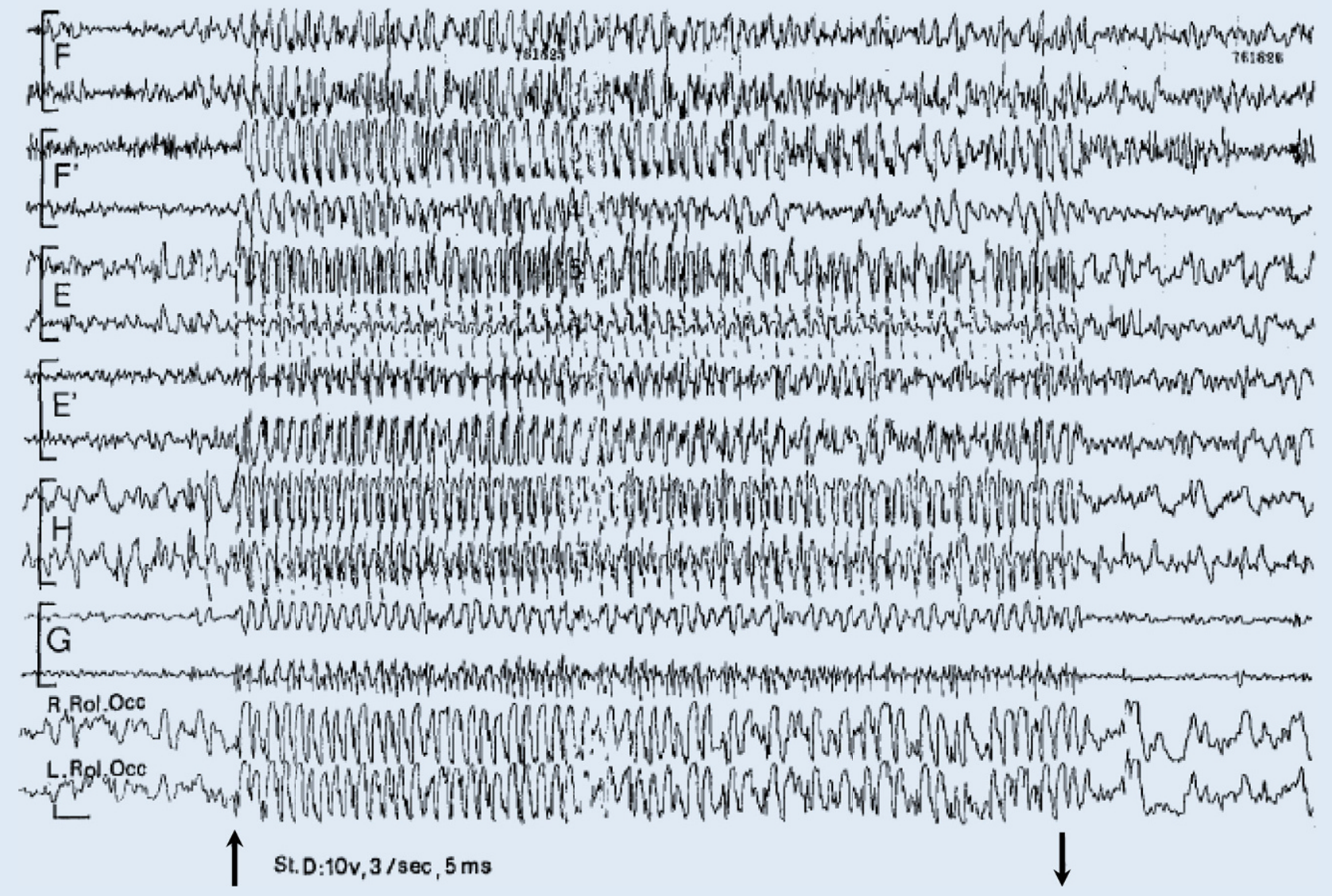

Fig. $5 \Delta$ Electroclinical "absence" on stimulation of the right mesial frontal lobe. At onset ( $\uparrow$ ) the patient stopped counting during bilaterally synchronous $3 / \mathrm{s}$ spike and wave, and he immediately resumed counting at termination $(\downarrow)$ of stimulation. (From [46]) (๑ Elsevier mit freundlicher Genehmigung)

tribution of molecular mechanisms at a microcircuitary or cellular level is still scarce.

Crunelli and Lereche [44] state that: "Several clinical and experimental findings have challenged the classical view of SWDs as generalized EEG paroxysms in favour of a 'focal' cortical origin. However, this view does not imply a localized cortical defect, as the lower threshold for the initiation of the discharges could simply reflect a higher sensitivity of the cortex to an abnormality that is expressed in both cortical and subcortical areas. From the cellular point of view, the EEG abnormalities that are associated with absence seizures involve mainly thalamic and cortical areas-that is, the thalamocortical loop. Studies in animal models have begun to establish the specific involvement of each cellular element of this loop in the expression of these seizures."
Experimental insight into details of complex pathophysiological concepts including basal ganglia is provided by Crunelli et al. [45]. They point out in the discussion: "From a neurobiological perspective, recent electrical recordings and imaging of large neuronal ensembles with single-cell resolution in non-anaesthetized models show that, in contrast to the predominant opinion, cortical mechanisms, rather than an exclusively thalamic rhythmogenesis, are key in driving seizure ictogenesis and determining spike-wave frequency."

\section{Frontal absences}

Bancaud et al. [46] elicited generalized epileptic seizures by electrical stimulation of the frontal lobe (- Fig. 5). In patients with frontal lesions, absence seizures and bilateral synchronous EEG discharges may occur.

Frontal lobe epilepsy surgery showed that even frontal lobe epilepsies with generalized bilateral spike-wave can be operated on successfully if the pacemakers relevant for the seizures can be removed. The regional epileptogenic areas are often widespread, including frontotemporo-central and even bilateral brain regions. Secondary bilateral synchrony was found in depth recordings of frontal lobe epilepsy in cases of epileptogenicity arising from the cingulate cortex, orbitofrontal cortex, or anterior frontal convexity [47]. Seizures from the fronto-opercular convexity or antero-frontal region were associated with a high incidence of automatisms. Stereo-EEG (SEEG) recordings identified patients with focal unilateral epileptic activity, bifrontal activity, or a continuum of focal, bifrontal, and mul- 

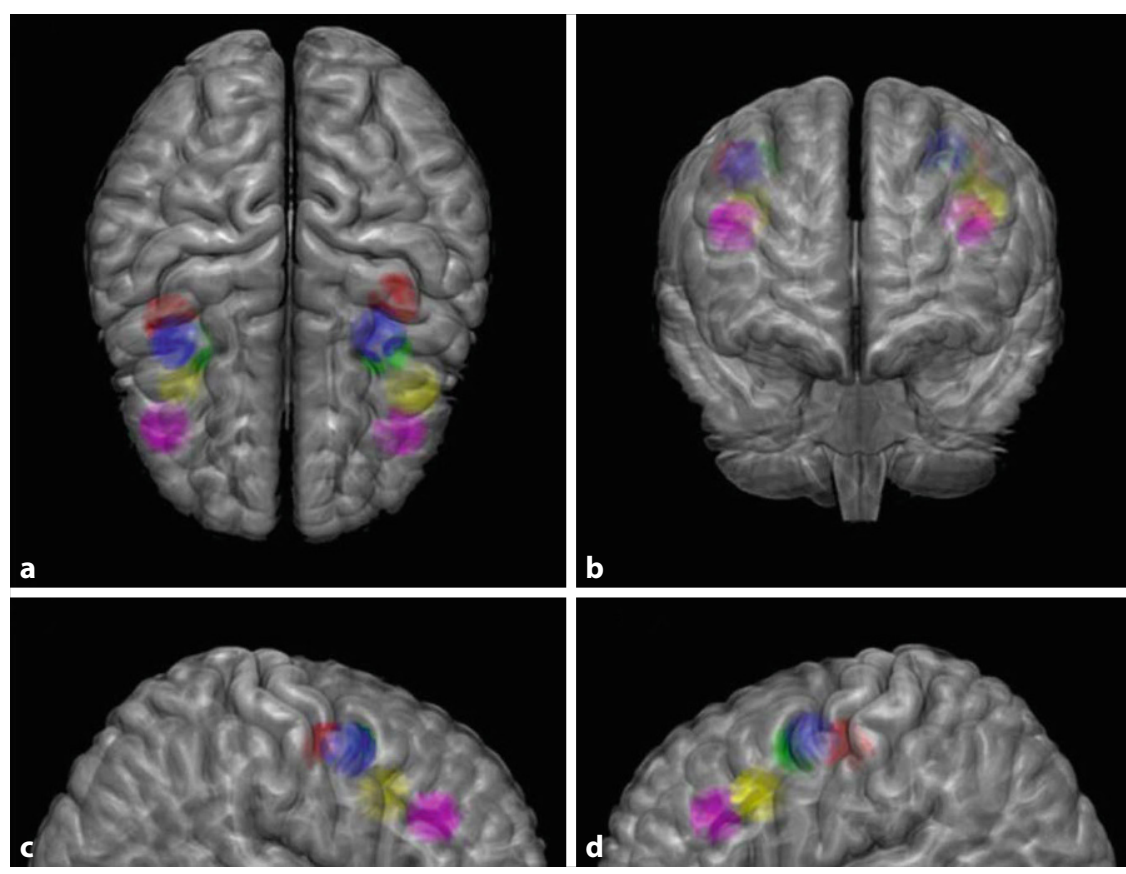

Fig. $6 \Delta$ Localization of frontal eye field (FEF) according to several studies on the MNI (Montreal Neurological Institute) brain template viewed from top (a), front (b), right (c), and left (d). Color codes as follows. Green: meta-analysis of positron emission tomography studies. Blue: functional magnetic resonance imaging (fMRI) study. Red: fMRI study. Yellow: magnetoencephalography study. Purple: coordinates estimated. A sphere of $1 \mathrm{~cm}$ radius is positioned at the center of FEF activation from each study [52] (๑ Oxford University Press, mit freundlicher Genehmigung)

tifocal activity. The results from frontal lobe epilepsy surgery demonstrate that the frontal lobe epileptogenic cortex can extend to large areas leading to bilateral extended spike-wave [47].

\section{॥) The distinction between generalized and focal epilepsy is at times imperfect}

Swartz [48] described patients with frontal lobe epilepsy (invasive seizure onset frontolateral). These patients presented clinically with absence seizures (duration 5-40 s) without 3/s spike-wave. As Fernandez-Baca Vaca and Park [24] stated: "The distinction between generalized and focal epilepsy is at times imperfect and some epilepsies have features that fall in between these two extremes." And further: "An overlap of focal and generalized epileptiform abnormalities may support a continuum between focal and generalized epilepsy. When evaluating patients in the 'gray zone', other factors such as ictal semiology, neuroimaging, genetic testing and functional deficits may need to be considered to reach an accurate diagnosis." For the differential diagnosis, one has to keep in mind, on the one hand, that focal absences, for example, due to a frontal tumor could be misdiagnosed as IGE, with accordingly significant consequences. On the other hand, absences with prominent focal signs in IGE may undergo intensive video-EEG monitoring for presurgical evaluation, without any clear benefit for the patient.

In a cohort of 59 consecutive children referred for staring spells, Pavone and Niedermeier [49] analyzed clinical and EEG characteristics in 23 children with both a history of absence seizures and a generalized spike-wave pattern during longterm video-EEG monitoring. In 10 children, a frontal spike preceded the generalized spike-wave pattern. In the remaining 13 children, primary generalized spikes and waves were found. The frontalonset absences were clinically not different from primary generalized absences. The most striking difference between the two groups was the difficulty in controlling the absences in the frontal-onset group; the incidence of learning and behavioral problems in this group was also comparatively high. The EEG analysis showed interictal, isolated epileptic discharges in $80 \%$ of the children with frontal-onset absences. According to the results, frontal-onset absences should be considered as a secondarily generalized epilepsy syndrome, originating in the frontal regions.

Jocic-Jakubi et al. [50] studied 30 children with CAE. According to their EEG pattern, two groups were defined: group $A$ comprised 11 children with classic absences whose ictal EEG showed primary generalized spikes and waves, and group $B$ included 19 children with frontal onset of the EEG epileptic abnormalities ("frontal group"). In the frontal group, complex absences were seen more often. For three children in the frontal group, ethosuximide had to be added to VPA monotherapy to achieve seizure freedom. In the frontal group, more learning and behavioral problems were observed. This study largely confirms a previous study by Lagae et al. [51]. It seems that frontal-onset absences constitute a specific subtype within the CAEs.

\section{》) Frontal-onset absences constitute a specific subtype of CAE}

Vernet et al. [52] discussed the frontal eye field (FEF) at the heart of the coupling between attention and eye movements (- Fig. 6). The cortical representation and extended function of the frontal eye field plays a role in the interpretation of the ictal semiology. In absence seizures, ocular ictal signs often are the initial core element of the recognized cranio-caudal march. "In analogy to the Jacksonian march of partial elementary motor seizures one can speak of a march of generalizing seizure activity of absence type. Short-lasting absences often have only ocular symptoms, longer lasting absences oral automatisms or motor activities of the extremities as well as gestural automatisms."

The FEF is conceived not only as an important area for preparing and triggering eye movements, but also as an essential region contributing to cognitive processes such as attentional orienting, visual awareness, conscious access, perceptual performance, and decision-making. However, these processes are probably mediated by activity within largely distributed cortico- 
Spike-wave series
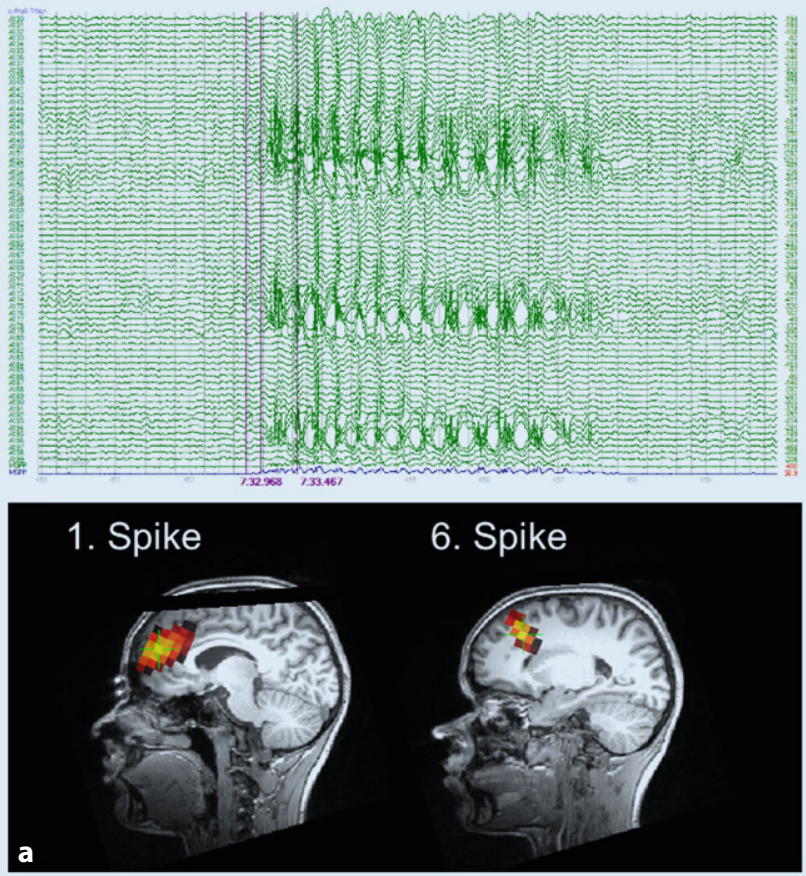

Single spike
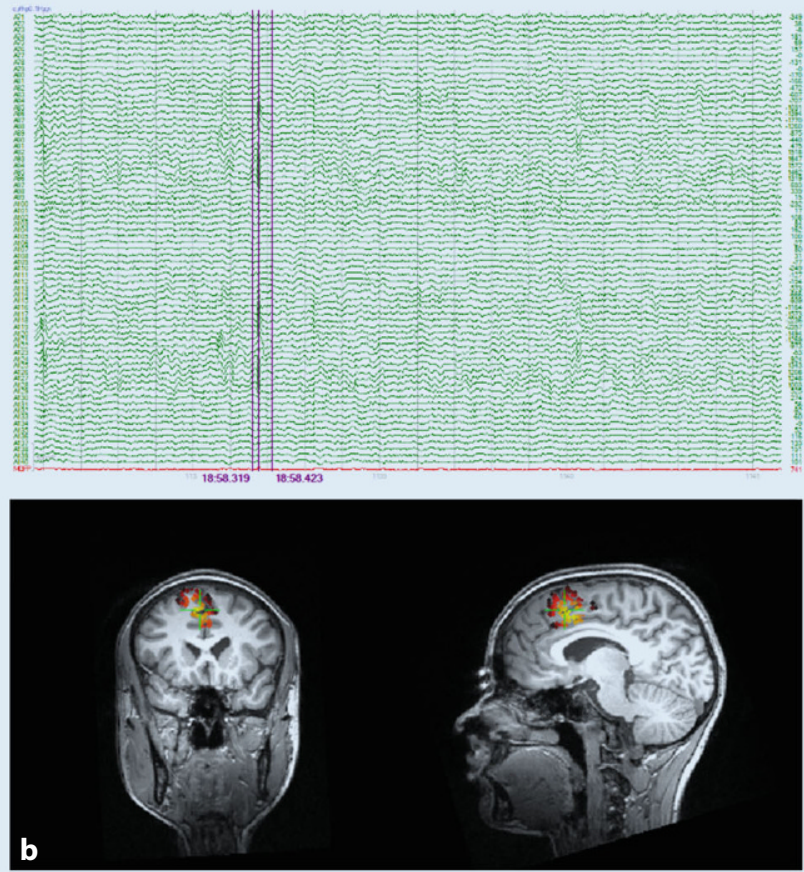

$\mathrm{c}, \mathrm{rfhp} 0.1 \mathrm{~Hz}, \mathrm{n}$

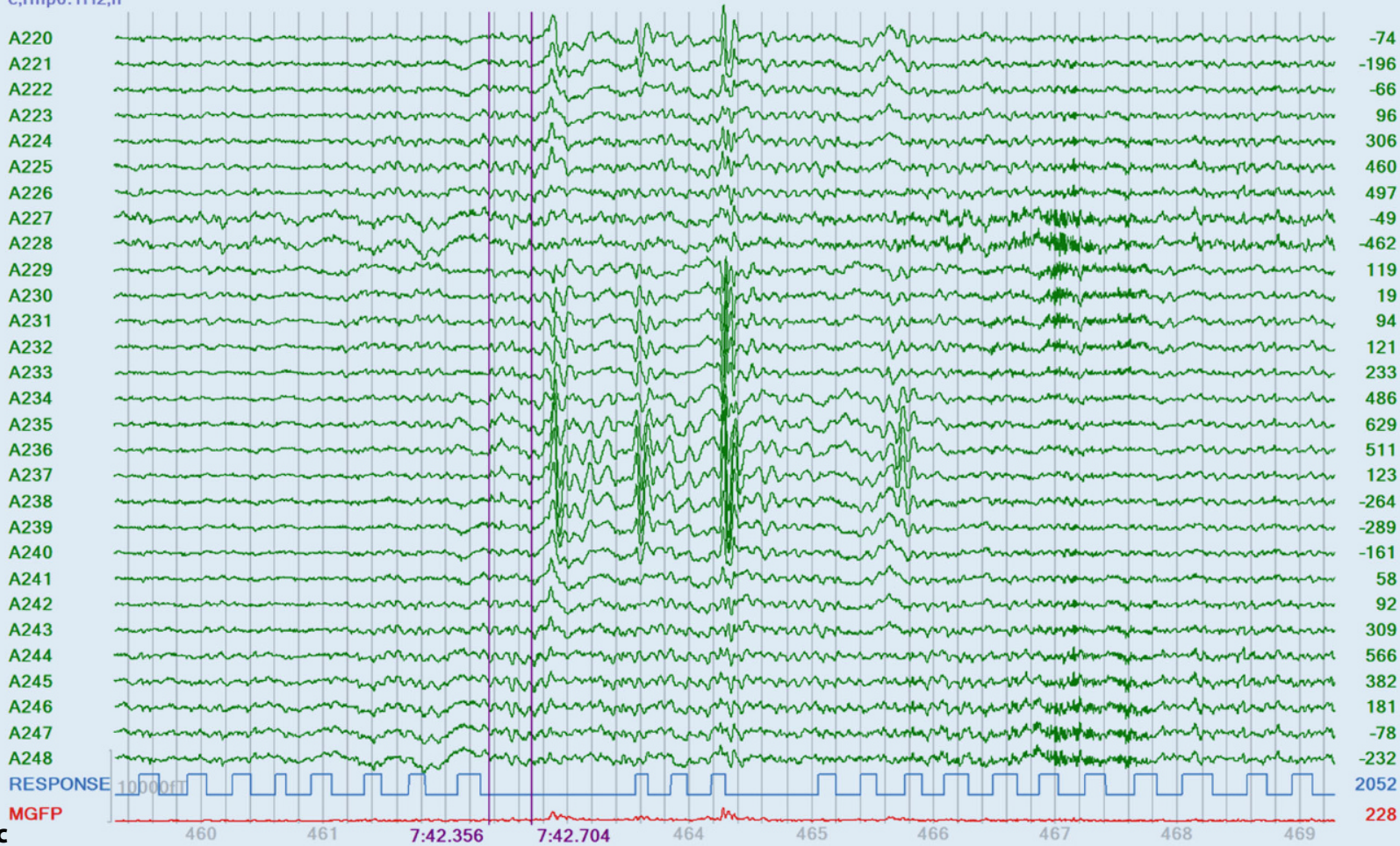

Fig. $7 \Delta$ An 18-year-old patient with idiopathic generalized epilepsy with absences and bilateral tonic-clonic seizures. a Top: Electroencephalography (EEG) showing bilateral spike-wave paroxysm 3-3.5/s; bottom: magnetoencephalography (MEG) localization, frontal (prefrontal-cingulate). b Top: EEG: single spike; bottom: MEG localization, frontomesial right (vicinity of pre-SMAregion). cMEG during reaction time measurement. During 2-s spike-wave paroxysm the patient stopped pressing the reaction button $300 \mathrm{~ms}$ before spike-wave paroxysm onset. This interruption lasts $800 \mathrm{~ms}$. After another $400 \mathrm{~ms}$, there is a second interruption of reaction performance lasting $500 \mathrm{~ms}$. The anterior cingulate cortex is involved in motor control and attention. The pre-SMA has extensive prefrontal connections such as the supplementary eye field. Further, it is involved in sequence learning $[54,55]$. Localization with sLORETAin a spherical volume conductor, activations of $>80 \%$ are shown (lighter colors show higher activation strength). (S. Rampp and H. Stefan, unpublished data) 
cortical and cortico-subcortical networks. In particular, frontoparietal systems are particularly relevant [52].

Electrophysiological findings of source localizations of spike-wave in the dorsal and mesial frontal lobe speak in favor of projections of field activity over the whole scalp surface in EEG [53].

With regard to localization in the frontal lobe, the case of a patient with presumed IGE illustrates the involvement of the aforementioned special frontal lobe regions responsible for motor and eye control and attention (- Fig. 7; [54, 55]).

Considering these results, there is no doubt that the frontal lobe-integrated in networks including special subcortical components-plays a major role in absence seizures.

\section{Network analysis}

\section{Network and behavior}

Historically accepted terms should be considered in the light of recently highlighted network aspects. How can we interpret focal characteristics of absences (which have been identified in animal experiments and clinical studies with high-resolution techniques) with modern network approaches?

Some examples can help us put the findings into context:

1. In rats with absences, a cortical focus was identified via invasive recordings [56]. "From this focus, seizure activity generalizes rapidly over the cortex. During the first cycles of the seizure the cortex drives the thalamus, while thereafter cortex and thalamus drive each other, thus amplifying and maintaining the rhythmic discharge." In this way the "cortical focus theory for generalized absence epilepsy bridges cortical and thalamic theories" [57].

2. With video-polygraphic recordings and slow-motion replay analysis, discrete focal motor signs even in unilateral temporal succession were documented, showing a high intraindividual consistency across motor activities [16].

3. Source reconstructions at the beginning of spike-wave paroxysms detected predominantly frontal epileptic activity with propagation [58-61].
4. Further investigations in JAE have revealed initially frontomesial focal epileptic activity to also be present in the posterior cingulate and precuneus. These activations correspond to an activated default network [62]. Wu et al. [63], investigating altered connectivity networks, stated that the frontal cortex and precuneus/posterior cingulate might play crucial roles in the pathophysiology of CAE. A focal pattern of bilateral frontal and parietal areas during the spikes alternating with generalized patterns during the waves was found for all children studied during generalization of the SWDs by Ossenblok et al. [64]. Although there are some common locations for epileptic cortices, individual variation in regional susceptibility of the cortex may lead to variability of excited networks.

5. Amor et al. [59] investigated the dynamics of brain activity by means of MEG in human absence epilepsy. Analysis of cortical local and long-range synchronization interplay revealed a multifocal frontocentral network involved in multiscale processes with local and distant interactions. Elshahabi et al. [65] investigated functional network connectivity using MEG in 13 patients with IGE and 19 control participants. In addition to widespread increase of connectivity, changes were found particularly in the motoric-mesio-frontal and temporal cortex. This corresponds to motoric activities in IGE as integral elements of the seizure manifestations.

6. Cortical and thalamic neuronal networks both contribute to the generation of bilateral spike-wave paroxysms. Studies using high temporal resolution (EEG, MEG) show discrete cortical networks initiating the process of excitation. Sysoeva et al. [66] found patients with absences already showing preictal changes in network dynamics. Bai et al. [67] observed small early fMRI increases in the orbital/medial frontal and medial/lateral parietal cortex $>5 \mathrm{~s}$ before seizure onset, followed by profound $\mathrm{fMRI}$ decreases continuing $>20$ s after seizure end. The thalamus showed delayed increases after seizure onset followed by small decreases.

7. Tangwiriyasakul et al. [68] used EEGfMRI to detect changes in connectivity $1 \mathrm{~min}$ before bilateral widespread spike-wave paroxysms. A significant increase inf connectivity existed in the sensorimotor network. In comparison to healthy controls, this network showed an augmented synchrony before spike-wave $(p=0.004)$. An additional increase of connectivity occurred prefrontally and in the precuneus $6 \mathrm{~s}$ before spike-wave paroxysm,. The abnormal excitatory activity of the entire brain required a cluster of neurons of local origin to initiate spike discharges, which caused the synchronous hyperexcitability in the epileptic network.

8. Wagner et al. [69] provided evidence that ictal rhythmic spike-wave discharges occurring in "primary generalized" absences were induced by optogenetic stimulation of excitatory cells in local neocortical areas.

9. According to Crunelli et al. [45], it is reasonable to believe that ictal spikes are important for spreading information from local areas to the whole brain network, and thus could be treated as a marker of epileptic seizure. Localized changes in neuronal excitability limited to a restricted cortical or thalamic neuronal cluster can induce bilateral widespread spike waves throughout cortico-thalamo-cortical networks, due to susceptible oscillating networks. Last but not least, if the cortical initiating network, e.g., in frontal accessible areas can be determined using transcranial electromagnetic stimulation, activation of light-sensitive proteins without surgical intervention, focused ultrasound, and other noninvasive treatment approaches can be kept in mind [45]. This requires intensifying a localization/related search of the corticothalamic network even in IGE seizures. This claim is supported by the development of absences in mice after knockout of a single gene (Cacna1a, coding for $\mathrm{P} / \mathrm{Q}$-type $\mathrm{Ca}^{2+}$ channels) in layer-6 pyramidal neurons [70].

Overall, experimental and clinical investigations have so far not been able to show 


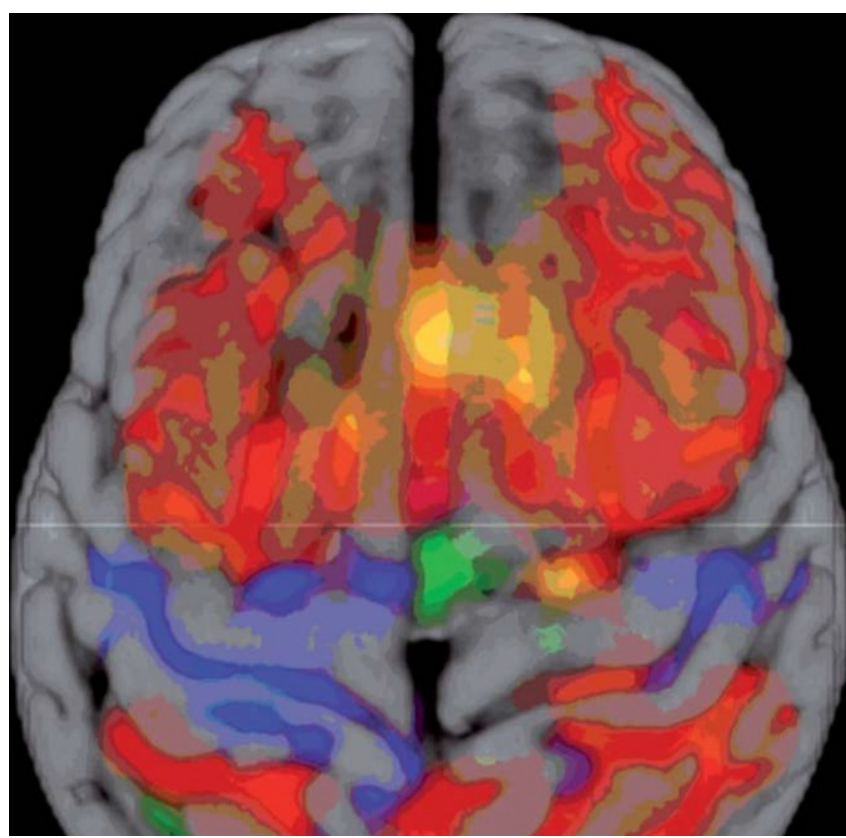

Fig. $8 \Delta$ Spatial relationship between findings. The figure summarizes some of the results to aid the interpretation of their spatial relationship. Activation from the working memory task in control participants is shown in red. Areas of increased activation in juvenile myoclonic epilepsy (JME), compared with controls, are shown in blue - mainly in the pre- and postcentral gyrus and SMA. The orange clusters show areas of increased functional connectivity to the motor cortex and SMA-mainly in the medial prefrontal cortex, overlapping with the task-induced activation. The green cluster shows the area of impaired deactivation during the cognitive task in JME. Gyral anatomy is overlaid from the MNI152_T1 template. The horizontal line indicates $y$. coordinate 0 in Montreal Neurological Institute space [73]

generalization in the strict sense at the beginning of an absence seizure. The cortical initiating network is the major player in the generation of absence seizures, keeping in mind that restricted neuronal populations of the thalamus and basal ganglia also belong to this network.

\section{॥) The cortical initiating network is the major player in generating absence seizures}

Koepp et al. [71], following Janz's seminal description, pointed out that juvenile myoclonic epilepsy is characterized not only by specific types of seizures, but also a particular personality profile indicating possible involvement of the frontal lobe. Their quantitative MRI studies revealed abnormalities of cortical gray matter in medial frontal regions, and spectroscopy showed thalamic dysfunction -indicating that JME could be a frontal lobe variant of a multiregional thalamocortical network epilepsy rather than a generalized epilepsy syndrome. Whole-brain voxel- based morphometry (VBM) detected reductions in gray matter volume in the supplementary motor area and posterior cingulate cortex, and neuropsychological examinations demonstrated subtle dysfunctions in verbal fluency, comprehension, and expression as well as nonverbal memory and mental flexibility. According to O'Muircheartaigh et al. [72], these results indicate dysfunction in the mesial frontal cortex, especially the supplementary motor area, and the posterior cingulate cortex in JME. Motor system hyperconnectivity in JME was shown by a cognitive fMRI study ([73]; 0 Fig. 8).

Wolf et al. [74] clearly stated that:

"The prevailing understanding of generalized epilepsy is shaped by the traditional definition that the responsible neuronal discharge takes place, if not throughout the entire grey matter, then at least in the greater part of it and simultaneously on both sides. This view is no longer tenable since concurrent findings using multiple methods have accumulated to reveal the role of bilateral networks of distributed and se- lective cortical and subcortical structures in socalled generalized ictogenesis. Recent research unites these new findings into a comprehensive nosological view. Genetically determined dysfunctions of important cognitive systems like visuomotor coordination and linguistic communication appear now as key mechanisms of seizure generation in JME. This review suggests a new paradigm to consider JME as a system disorder of the brain analogous to other neurological system disorders."

\section{Treatment responses}

The traditional view on the prognosis of IGE with absences has been dominated by the famous title of Pierre Loiseau's publication: "Le petit mal qui guérit, guérit rapidement" [Petit mal which can be cured is cured rapidly] [75].

A historical overview of the treatment success in CAE patients is provided by Morse et al. [76]: This analysis included 29 studies of 2416 patients, published between 1945 and2013. Seizure freedom was higher for studies after 1985 as compared to studies before 1975 ( $82 \%$ vs. $35 \%$; $p<0.001$ ). Japardize et al. [22] reported that in 118 patients with JAE and JME, $90.7 \%$ became seizure-free within 1 year. The authors stated that focal EEG features are common, but do not influence the therapeutic response.

Von Podewills et al. [77] found in 15 untreated patients with IGEs (mean duration of follow-up: 15.3 years) that the rate of remission for absence epilepsies was $80 \%$, for tonic-clonic seizures it was $60 \%$, and for the combination of both, only $20 \%$.

Gomez-lbanez et al. [78] analyzed 279 patients with drug-resistant IGE. The multivariate analysis pointed to greater probability of unfavorable treatment outcome in cases of a combination of seizure types, status, EEG with polyspikes, and drug side effects.

Capovilla et al. [79] examined 12 patients with CAE, presenting with typical absence seizures associated with myoclonic manifestations of the face or neck recorded using split-screen video-polygraphic EEG recordings. During the absences, the patients showed mild, rhythmic, myoclonic jerks involving facial areas (eyebrows, nostrils, perioral region, chin) or neck mus- 
cles (sternocleidomastoid muscle), with the same frequency as the spike-wave complexes. Polygraphic tracings revealed that the myoclonic manifestations were correlated to the spike component. The patients became seizure-free. They concluded that all patients showed an electroclinical picture consistent with CAE. The occurrence of myoclonic manifestations of the face or neck associated with the absences in the CEA patients did not influence the benign course of their disease. The electroclinical features observed in this group of patients are different from those in patients with myoclonic absences and from absences with perioral myoclonia.

The long-term prognosis of childhood and juvenile absence epilepsies in 163 patients with a mean follow-up period of 25.8 years was studied by Trinka et al. [80]. Overall, $56 \%$ of patients with CAE and $54 \%$ with JAE were seizure-free for at least 2 years. Later development of myoclonic or tonic-clonic seizures led to a long-term lack of remission. In another long-term study, 135 patients with absence epilepsy (123 with additional tonic-clonic seizures) were retrospectively analyzed after a median follow-up of 45.4 years. In total, $53 \%$ achieved 5-year terminal seizure remission, $16 \%$ without antiepileptic medication [81].

\section{I) The clinical course may have predictive value}

Callenbach et al. [82] determined the long-term outcome and the predictive value of baseline and EEG characteristics on seizure activity evolution in 47 children with newly diagnosed CAE. The followup lasted 12-17 years. Three groups were used for the analyses: seizurefree (I) within 1 month after enrollment; (II) 1-6 months after enrollment; and (III) more than 6 months after enrollment or having seizures continuing during follow-up. All groups had high remission rates after $12-17$ years. Significantly more relapses occurred in group III than in group I. The total duration of epilepsy and mean age at final remission were 3.9 and 9.5 years, respectively, being significantly longer and higher in group III than in groups I and II. The CAE patients had an overall good prognosis, with few children (7\%) not becoming seizure-free. The early clinical course (i.e., the first 6 months) has some predictive value with respect to the total duration of absence epilepsy.

Kessler [83] found an association between seizure pattern subtypes and a reduced tendency of seizure-free outcome at week 16-20 in previously untreated patients. The effect was interpreted as a marker for a more medication-resistant phenotype. This corresponds to our findings indicating a slight trend for better treatment response in absences with ocular-rhythmic activity compared to motorically unproductive semiology [16].

Grosso et al. [84] analyzed the role of diagnostic criteria in their study including 119 CAE patients. Remission rates of patients with CAE were greatly influenced by the classification criteria used for selection. Stricter diagnostic criteria enable the definition of a homogeneous group of patients with excellent prognosis. Factors predicting unfavorable prognosis were generalized tonic-clonic seizures in the active stage of absences, myoclonic jerks, eyelid myoclonia or perioral myoclonia, and EEG features atypical for CAE.

Höfler et al. [85] studied the long-term course of 175 IGE patients with a median age at seizure onset of 15 years, and a median age at follow-up of 38 years. Seizure outcome was: 62\% (109/175) were seizure-free of myoclonic seizures, generalized tonic-clonic seizures, and absence seizures for $>1$ year, and 53\% (94/175) for $>2$ years, including 16 patients (9\%) without antiseizure medicines (ASMs). In total, $31 \%$ were seizure-free between 2 and 5 years, $15 \%$ between 6 and 10, and $8 \%>10$ years; $38 \%$ were not seizure-free. Patients who were not seizure-free were more likely to have myoclonic seizures, absence seizures, and generalized tonic-clonic seizures within the first year of epilepsy than those who were seizure-free.

In a study of 1530 patients with JME, 20.5\% were intractable. Polytherapy, switched regimens, and high doses were often used. Therefore, the authors suggest that JME is less likely to have a benign course [86].

Kitazawa et al. [87] showed in 12 patients with JME and 12 with non-JME that the presence of interictal focal epileptic activities and a family history of epilepsy are significantly associated with higher ASM load required to achieve seizure freedom.

In the study by Caplan et al. [88], $25 \%$ of children with $C A E$, compared with the normal group, had subtle cognitive deficits, 43\% linguistic difficulties, 61\% a psychiatric diagnosis, particularly attention deficit hyperactivity disorder (ADHD) and anxiety disorders, and 30\% clinically relevant child behavior checklist $(\mathrm{CBCL})$ broad band scores. Duration of illness, seizure frequency, and ASMs were related to the severity of the cognitive, linguistic, and psychiatric comorbidities. Only $23 \%$ of the CAE patients were receiving treatment or assistance for these problems.

Due to the high rate of impaired behavior and emotional or cognitive problems, early identification and treatment of children with CAE is required, particularly for those with longer duration of illness, uncontrolled seizures, and ASM treatment. Ethosuximide and valproic acid was shown to be more effective than lamotrigine in a randomized controlled study of the treatment of CAE (without additional tonic-clonic seizures). Ethosuximide is associated with fewer adverse attentional effects [89]. The beneficial effect of ethosuximide acid in pure absence epilepsy may reflect the specific pathophysiological composition in cases of absences not belonging to an exclusively focal cortical or a universal excitation in the brain. The use of valproic acid, which represents the most useful broad-spectrum ASM for IGE, is restricted in women of childbearing age $[90,91]$. When considering new treatment approaches in IGE, there is a clear unmet need for better, well-tolerated, and effective treatments to overcome drug resistance and neuropsychiatric comorbidities of IGE with absences [92]. Some examples are, e.g., cannabidiol, which is being tested in phase 2 trials in children with drug-resistant absence seizures; a pan-T-channel antagonist blocking experimental absence seizures and ameliorating some aspects of their comorbidity is in a phase 2 trial in an adult population with pharmacoresistant absence seizures; drugs that increase the activity of GAT-1 and antagonists of d-containing GABA-A-receptors; as well as allosteric modulators of metabotropic glutamate receptors (overview by Crunelli et al. [45]). 


\section{Future research approaches}

Research in the past three decades clearly points to a differential network activation in IGEs with absences, rather than a purely generalized concept. Future investigations can take this into account using multidimensional approaches.

\section{Genetics}

Genetic and pathophysiological studies in models of absence seizures can help to identify more clearly the mechanisms that underlie spike-wave discharges and other electrophysiological characteristics. More precise classifications of CAE could also facilitate the discovery of the genetic traits of CAE [44]. Genetic mechanisms including gene variants may produce symptoms particularly associated with distinct networks [93]. Epileptic activity can be a surrogate for an underlying etiology. Pathologic gene variants produce symptoms referable to multiple brain networks. What molecular and circuit mechanisms cause specific involvement of specific regions, such as significant contributions of frontal areas to thalamic dysregulation?

\section{Endophenotype}

Using graph theoretical network analysis, Elshahabi et al. [65] found a widespread increase in connectivity in patients with IGEs compared to controls. These changes were most pronounced in the motor network, the mesiofrontal and temporal cortex. The findings suggest that increased resting state connectivity could be an important factor for seizure generation and spread in IGE, and could serve as a biomarker for the disease.

Because for IGEs a polygenetic disposition is suggested and connectivity of brain networks can be heritable, the research concerning endophenotypes is of interest $[94,95]$. Connectivity analysis may identify predominant involvement of brain regions with regard to endophenotype analysis and become widely available in the near future $[96,97]$.

\section{Precision therapy}

If different endophenotypes of IGE manifestations can be defined, the classification of syndromes may be substantially improved and an opportunity for networkdriven therapeutic approaches could be provided. This could also include the risk assessment of additional development of seizure types other than pure absences. The distribution of spatial complexity of EEG in IGE and its change after chronic valproate therapy was investigated by Kandokor et al. [98].

Valproate therapy decreased the global complexity and increased regional complexity in the anterior region. Furthermore, VPA changed the distribution of spatial synchrony toward that of normal controls.

\section{I) The composition of the epileptic network may influence drug responsiveness}

Szaflarski et al. [99] reported that VPA-resistant and VPA-responsive patients may have different spike-wave generators and that these differences in generalized seizures may be the reason for different responses to VPA. Yeom et al. [100] found that an initial ASM failure was associated with temporal involvement in the current source distribution of CAE patients. This electrophysiological information, also called "pharmaco-EEG," may be helpful in clinical practice by enabling estimation in advance of the efficacy of initial ASM treatment in ASM-naïve CAE patients. These results are concordant with the emerging concept that the composition of the epileptic network may influence drug responsiveness in IGE and CAE. Pharmaco-EEG is now increasingly applied as a tool for earlier prediction of individual ASM responses [101].

\section{Objective seizure recording}

Objective registration of seizures has become possible by means of long-term recordings for in- and outpatients [102]. In addition to the measurement of the diurnal seizure frequency, the duration of seizures can be documented and chronotherapeutic approaches may be facilitated in order to obtain optimally personalized drug treatment with low dose, simple handling, and avoiding side effects $[103,104]$.

Circadian and sleep influences play a significant role in the manifestation of absence symptoms [105]. Therefore, chronobiological approaches in difficultto-treat patients are of great interest. The minimal necessary drug load for monoor combination therapy could be also investigated. Further research concerns the correlation of cognitive impairment with the amount of interictal or ictal epileptic activity.

\section{Stimulation treatments}

Is vagus nerve stimulation (VNS) a treatment option for patients with drugresistant IGE? It was reported that VNS led to a reduction in the frequency and intensity of seizures: $62 \%$ of patients showed a reduction in generalized tonic-clonic seizures $(p=0.0020), 58 \%$ of absences $(p=0.0003)$, and $40 \%$ of myoclonic seizures $(p=0.0156)$. Eight patients were considered responders ( $>50 \%$ seizure reduction); two of these patients became seizure-free [106]. Franzioni et al. [107] underlined the fact that a patient presenting with absence drug-resistant epilepsy showed a reduction in seizure frequency of $91.7 \%$ and a reduction in seizure duration of more than $50 \%$ after 9 months of VNS treatment. Before the implantation, seizure duration was from 20 to $40 \mathrm{~s}$ in every EEG, whereas after VNS implantation it was lower, and never longer than $20 \mathrm{~s}$. This was confirmed after 29 months of follow-up.

Araya et al. [108] observed the treatment course with VNS stimulation in nine VNS drug-resistant absence patients (seven CAE, two JAE). After a mean follow-up of 33.9 months ( \pm 25.5 , minimum 4 months), one patient attained complete seizure freedom (ILAE class 1), six had ILAE class 4, and two had ILAE class 5 outcomes. The mean reduction in daily seizure frequency was found to be $53.5 \pm 60.3 \%$ (one-sided $p$-value for paired $t$ test $=0.04$ ), with a $50 \%$ responder rate of $55.6 \%$. It was concluded that VNS may be considered as a therapeutic option for patients with medically refractory absence epilepsy. 
All these findings require further investigations using well-defined patient populations and a randomized controlled trial design. The question also arises of whether noninvasive trigeminus or vagus stimulation is a better tolerated option. Other considerations for future moves toward innovative treatment are the cortical initiating network, e.g., if frontal accessible areas can be determined by means of examining the circuit elements. Innovative noninvasive treatment approaches may be promoted [45]. This requires an intensified localization-related network search even in IGE seizures. Last but not least, Paz and Huguenard [109] contemplate:

"All seizures, even those associated with what have historically been thought of as 'primary generalized' epilepsies appear to originate within local microcircuits and then propagate from that initial ictogenic zone. Seizures propagate through cerebral networks and engage microcircuits in distal nodes - a process that can be weakened or even interrupted by suppressing activity in such nodes. While we need to identify the 'focus' of the initial dysfunction, we also need to look for potential control or choke points that are remote and could be distant from the 'focus' of the initial dysfunction. Thus, by scanning regions outside that of the initial insult, we may find 'foci' far from what has historically been considered the focus, and, in so doing, may find unique opportunities for effective therapies that target these circuits targeting such subcortical structures, such as the thalamus or substantia nigra, remote from the initial cortical dysfunction, might have major advantages. We propose that the thalamus could be a choke point in epileptic circuits in the same way that the subthalamus is a choke point for abnormal circuit dynamics in Parkinson's disease. Counter inhibition-inhibition of inhibition-affects thalamic function and has been implicated in ictogenesis in absence epilepsy."

\section{Conclusion}

In the last three decades of research on absences and IGEs, new information changed the traditional dichotomous concepts, challenged older theories, such as the centrencephalic system, and led to new hypotheses and theoretical frameworks.
Where do we stand today with terms like "focal" and "generalized"? Are these terms theoretically correct? No. Are they conceptionally and pragmatically useful? Yes.

The term "generalized" fits a simplified pragmatic approach, which is used for practical work. It poses a risk for future research, in that the underlying diversities relevant for precision therapies are only insufficiently considered.

If focal interictal or ictal signs are observed then they cannot be swept under the carpet. Otherwise, the meaning of the term "focal" will fade in its unambiguity.

How can one distinguish the early preictal and ictal cortical activity of absence seizure as "a phenomenon very distinct from the structural and functional alterations" that characterizes the "focus" of focal onset seizures? [9].

The rules on the use of these terms should be adapted according to increasing knowledge, and dogmatism should be substituted by empiricism. Korff and Nordli [110] proposed that seizures undetermined as either focal or generalized (or multifocal) could be called "pleomorphic," and according to Wolf et al. [74], the epilepsy syndromes could be categorized as "system disorder."

It should be considered that seizures in IGEs have bilateral widespread and focal characteristics with integral involvement of the motor system. In IGEs with bilateral spike-wave and focal features, the genetic disposition-indicated by spike-waves that can be associated with predominantly favorable outcomes - may outweigh the clinical impact of a focal component, although this may not be true for certain subpopulations.

Network research, genetics, and endophenotyping may provide more insight for the differentiation, risk assessment, and management of IGE syndromes with absences.

\section{Corresponding address}

Univ. Prof. Dr. Hermann Stefan

Department of Neurology-Biomagnetism, University Hospital Erlangen

Schwabachanlage 6, 91054 Erlangen, Germany hermann.stefan@t-online.de
Funding. Open Access funding enabled and organized by Projekt DEAL.

\section{Declarations}

Conflict of interest. H. Stefan and E. Trinka declare that they have no competing interests.

All studies performed were in accordance with the ethical standards indicated in each case.

Open Access. This article is licensed under a Creative Commons Attribution 4.0 International License, which permits use, sharing, adaptation, distribution and reproduction in any medium or format, as long as you give appropriate credit to the original author(s) and the source, provide a link to the Creative Commons licence, and indicate if changes were made. The images or other third party material in this article are included in the article's Creative Commons licence, unless indicated otherwise in a credit line to the material. If material is not included in the article's Creative Commons licence and your intended use is not permitted by statutory regulation or exceeds the permitted use, you will need to obtain permission directly from the copyright holder. To view a copy of this licence, visit http://creativecommons.org/licenses/by/4.0/.

\section{References}

1. Esquirol J (1815) Epilepsie. In: Adelon MM et al (ed) Dictionaire des Sciences Médicales. Societe de Medicines et de Chirurgiens, Paris, pp 510-538

2. Temkin $O$ (1971) The falling sickness, 2nd edn. Hopkins, Baltimore

3. Calmeil L (1824) Delèpilepsie, etudie' sos le rapport de son siege et de son influence sur la production delàlienation mentale

4. Herpin T (1867) Des acces incomplets dèpilepsie. Bailliere, Paris

5. Brigo F, Trinka E, Lattanzi S, Bragazzi NL et al (2018) A brief history of typical absence seizures-petit mal revisited. Epilepsy Behav 80:346-353

6. Temkin O (1971) The falling sickness-a history of epilepsy from the Greeks to the beginnings of modern neurology. John Hopkins University Press, London

7. Commission on Classification and Terminology of the International League Against Epilepsy (1981) Proposal for revised clinical and electroencephalographic classification of epileptic seizures. Epilepsia 22:489-501

8. Commission on Classification and Terminology of the International League Against Epilepsy (1989) Proposal for revised classification of epilepsies and epileptic syndromes. Epilepsia 30:389-399

9. Scheffer IE, Berkovic S, Capovilla G, Connolly MB (2017) ILAEclassification of the epilepsies: position paper of the ILAE commission for classification and terminology. Epilepsia 58:512-521

10. Unterberger I, Trinka E, Kaplan PW, Walser G et al (2018) Generalized nonmotor (absence) seizureswhat do absence, generalized, and nonmotor mean? Epilepsia 59(3):523-529

11. Rosenthal G (1935) Die gehäuften kleinen Anfälle des Kindesalters. In: Czerny VA (ed) Ergebnisse der inneren Medizin. Springer, Berlin

12. Janz D (1955) Die klinische Stellung der Pyknolepsie. Dtsch Med Wochenschr 80:1392-1400

13. Gastaut H, Broughton J, Roger C, Tassinari A (1974) Generalized nonconsulviv seizures wthout local 
onset. In: Vinken P, Broyn G (eds) Handbook of clinical neurology, vol 15. North Holland Publ, Amsterdam

14. Penry J, Porter R, Dreifuss F (1975) Simultaneous recording of absence seizures with video tape and electroencephalograpphy. Brain 98:427-440

15. Stefan H, Burr W, Hildebrand K, Penin H (1981) Computer supported documentation in the video analysis of absences, preictal, ictal phenomena:polygraphic. 12th Epilepsy international Symposium. Advances in epileptology. Raven Press, New York

16. Stefan H (1982) Epileptische Absencen: Studien zur Anfallsstruktur, Pathophysiologie und zum klinischen Verlauf. Thieme,

17. Stefan H, Snead OC III (1997) Absence seizures. In: Engel J Jr, Peadly T (eds) Epilepsy. A comprehensive textbook. Lippincott Raven Publishers, Philadelphia

18. Stefan H, Burr W, Penin H (1983) Time structure analysis of motor phenomena in absence epilepsies. In: Speckmann EJ, Elger C (eds) Epilepsy and motor system. Urban und Schwarzenberg, München, Wien, Baltimore

19. Shylaja N, Negoro T, Watanabe K, Aso K (1993) Focal and generalized EEG-paroxysms in childhood absence. Brain Dev 15:91-96

20. Sadleir LG, Smith S, Connolly MB, Farrell K (2009) Automatisms in absence seizures in children with idiopathic generalized epilepsy. Arch Neurol 66(6):729-734

21. Panayiotopoulos CP, Obeid T, Waheed G (1989) Differenriation of typical absence seizures in epileptic syndromes. A video EEG Study of 224 seizures in 20 patients. Brain 112(4):1039-1056

22. Japardize G, Kasrate S, Lomiz G, Zhiziasvilli L et al (2016) Focal EEG features and therapeutic response in patients with juvenileabsenceepilepsy and myoclonic epilepsy. Clin Neurophysiol 127:1182-1187

23. Seveniratne U, Cook MD, Souza W (2015) Focal abnormalities in idiopathic generalized epilepsy: a critical review of the literature. Epilepsia 55(8):1157-1169

24. Fernandez-Baca Vaca G, Park JT (2020) Focal EEG abnormalities and focal ictal semiology in generalized epilepsy. Seizure 77:7-14

25. Woermann F, Sisodiya SM, Duncan JS (1998) Quantitative MRI in patients with idiopathic generalized epilepsy. Evidence of widespread cerebral structural changes. Brain 121(9):1661-1667

26. Kim EH, Shim WH, Lee JS, Yoon HM et al (2020) Altered structural network in newly onset childhood absence epilepsy. J Clin Neurol 16(4):573-580

27. Doelken M, Mennecke A, Stadlbauer A, Doerfler A et al (2010) Multi-voxel magnetic resonance spectroscopy at 3T in patients with idiopathic generalised epilepsy. Seizure 19(8):485-492

28. Kapuca L, Serdaroglu A, Okuyac C, Kone G et al (2003) Brain single photon emission computed tomographic evolution in patients with childhood absence epilepsy. J Child Neurol 18:542-548

29. Moeller F, Mona M, Pittau F, Gholipour Tet al (2011) Functional connectivity in patients with idiopathic generalized epilepsy. Epilepsia 52(3):555-522

30. Kasper B, Chang B, Kasper E (2009) Microdysgenesis: historical roots of an important concept in epilepsy. Epilepsy Behav 15(2):146-153

31. Meencke H, Janz D (1984) Neuropathological findings in primary generalized epilepsy: astudy of eight cases. Epilepsia 25(1):8-21

32. Janz D (1985) The significant micro dyskinesia in primary generalized epilepsy: an answer to the considerations of Lyon and Gastaut. Epilepsia 26(4):368-371

33. Opeskin K, Kalnins R, Halliday G, Cartwright H, Berkowic S (2000) Idiopathic generalized epilepsy:lack of microdysgenesis. Neurology 55(8):1101-1106

34. Jackson JH (1873) On the anatomical, physiological, and pathological investigation of epilepsies. West riding lunatic asylum medical reports, vol 3 , p347

35. Moruzzi G, Magoun HW (1995) Brain stem reticular formation and activation of the EEG. 1949. JNeuropsychiatry Clin Neurosci 7(2):251-267

36. Jasper H (1969) Diffuse projection systems: the integrative action of the thalamic reticular system. Electroencephalogr Clin Neurophysiol 1:405-420

37. TükelK, Jasper H(1952) The electroencephalogram in parasagittal lesions. Electroencephalogr Clin Neurophysiol 4:481-494

38. Gloor P (1969) Generalized cortico-reticular epilepsies. Some considerations on the pathophysiology of generalized bilaterally synchronous spike and wave discharge. Epilepsia 9:249-263

39. Gloor P (1979) Generalized epilepsy with spikeand-wave discharge: a reinterpretation of its electrographic and clinical manifestations. The 1977 William G. the second lecture, American epilepsy society. Epilepsia 20(5):571-588

40. Niedermeyer E (1969) Primary (idiopathic) generalized epilepsy and underlying mechanisms. Clin Electroencephalogr 27:1-21

41. Lüders H, Turnbull J, Kaffashi F (2009) Are the dichotomies generalized versus focal epilepsies and idiopathic versus symptomatic epilepsies still valid in modern epileptology? Epilepsia 50(6):1336-1343

42. Blumenfeld H (2005) Consciousness and epilepsy:why are patients with absences $a b$ sent? Prog Brain Res 150:271-286

43. Koutroumanidis M, Kostopoulos GK, Tsiptsios D, Kokkinos V (2012) Focal and generalized EEG paroxysms in childhood absence epilepsy: topographic associations and distinctive behaviors during the first cycle of non-REM sleep. Epilepsia 53(5):840-849

44. Crunelli V, Lereche N (2002) Childhood absence epilepsy: genes, channels, neurons and networks. Nat Rev Neurosci 3:371-382

45. Crunelli V, Magor L, Lorincz ML, McCafferty C et al (2020) Experimental insight into pathophysiology, comorbidity and therapy of absence seizures. Brain 143:2341-2368

46. Bancaud J, Talairach J, Morel P, Bresson M et al (1974) "Generalized" epileptic seizures elicited by electrical stimulation of the frontal lobe in man. Electroencephalogr Clin Neurophysiol 37:275-28256

47. Quesney LF, Constain M, Rasmussen T, Stefan $H$, Olivier A (1992) How large are frontal lobe epileptogenic zones? EEG, ECoG, and SEEG evidence. Adv Neurol 57:311-323

48. Swartz B (1992) Pseudo absence: a frontal lobe phenomenon. JEpilepsy 5(2):80-93

49. Pavone A, Niedermeier E (2000) Absence seizures and the frontal lobe. Clin Electroencephalogr 31(3):153-156

50. Jocic-Jakubi B, Jovanovic M, Jankovic DS, Lagae L (2009) Frontal-onset absences in children: associated with worse outcome? A replication study. Seizure 18(4):275-278

51. Lagae L, Pauwels J, Monte B, Verhelle J, Vervisch J (2001) Frontal absences in children. Eur J Pediatr Neurol 5:243-255
52. Vernet M, Quenti R, Chanes L, Mitsumasu A, Valero-Cabre A (2014) Frontal eye field, where art thou? Anatomy, function, and non-invasive manipulation of frontal regions involved in eye movements and associated cognitive operations. Front Integr Neurosci 1 (8):88

53. Gavaret M, Badier JM, Marquis P, McGonigal A et al (2006) Electric source imaging in frontal lobe epilepsy. J Clin Neurophysiol 23:358-370

54. Nachev P (2007) The role of the pre-SMA area in the control of action. Neuroimage 36(2):T155-163

55. Shimizu T (2020) Localization with SLORETA in a spherical volume conductor, activation > $80 \%$ are shown (lighter colors show higher activation strength). Sci Direct 13(1):229-238

56. Meeren KM, Pijn JP, Van Luijtelaar E, Coenen A, Lopes da Silva FH (2002) Cortical focus drives widespread corticothalamic networks during spontaneous absence seizures in rats. J Neurosci 22(4):1480-1495

57. Meeren H, van Luijtelaar G, Lopes da Silva F, Coenen A (2005) Evolving concepts on the pathophysiology of absence seizures: the cortical focus theory. Arch Neurol 62:371-37655

58. Holmes M, Brown N, Tucer D (2004) Are generalized seizures truly generalized? Epilepsia 45(12):1568-1579

59. Amor F, Baillet S, Navarr V, Adam C et al (2009) Cortical local and lomg-range synchronization interplay in human absence seizure initiation. Neuroimage 45(3):950-962

60. Westmijse I, Ossenblock P, Gunning B, Luijtellar G (2009) Onset and propagation of spike and slow wave discharges in human absence epilepsy: a MEG study. Epilepsia 50(12):2538-2548

61. Stefan H, Pauli E, Hopfengärtner R, Rampp S (2009) Network charachteristics of idiopathic generalized epilepsies in combined MEG/EEG. Epilepsy Res 85(2-3):187-198

62. Sakurai K, Takeda Y, Tanaka N, Kurita T (2010) Generalized spike-wave discharges involve a default mode network in patients with juvenile absence epilepsy: a MEG study. Epilepsy Res 89:176-184

63. Wu C, Xiang J, Jiang W, Huang S et al (2017) Altered effective connectivity network in childhood absence epilepsy: a multi-frequency MEG study. Brain Topogr 30(5):673-678

64. Ossenblok $P$, van Houdt $P$, Colon A, Stroink $H$, van Luijtelaar $G$ (2019) A network approach to investigate the bi-hemispheric synchrony in absence epilepsy. Clin Neurophysiol 130(9):1611-1619

65. Elshahabi A, Klamer S, Sahib Ket al (2015) Magnetoencephalography reveals a widespread increase in network connectivity in idiopathic/genetic generalized epilepsy. PLoSONE 10(9):e138119

66. Sysoeva M, Sitnikova E, Syseov I, Bezruchko B, van Luitelaar G (2014) Application of adaptive nonlinear Granger causality: disclosing network changes before and after absence seizure onset in a genetic ratmodel. JNeurosci Methods 226:33-41

67. Bai X, Vestal M, Berman R, Negishi M et al (2010) Dynamic time course of typical childhood absence seizures: EEG, behavior, and functional magnetic resonance imaging. JNeurosci 30(17):5884-5893

68. Tangwiriyasakul C, Perani S, Centeno $M$ et al (2018) Dynamic brain network states in human generalized spike-wave discharges. Brain 141(10):2981-2994

69. Wagner F, Truccolo W, Wang J, Nurmikko A (2015) Spatiotemporal dynamics of optogenetically induced and spontaneous seizure transitions in primary generalized epilepsy. J Neurophysiol 113(7):2321-2341 
70. Bomben VC, Aiba J, Mark M, Herlitze S et al (2016) Isolated $\mathrm{P} / \mathrm{Q}$ calcium channel deletion in layer $\mathrm{VI}$ corticothalamic neurons generates absence epilepsy. J Neurosci 36(2):405-418

71. Koepp M (2005) Juvenile myoclonic epilepsy-a generalized epilepsy syndrome? Acta Neurol Scand 181:57-62

72. O'Muircheartaigh C, Vollmar GJ, Barker V et al (2011) Focal structural changes and cognitive dysfunction in juvenile myoclonic epilepsy. Neurology 76(1):34-40

73. Vollmar V, O'Muircheartaigh J, Barker GJ, Symms MR, Thompson P et al (2011) Motor system hyperconnectivity in juvenile myoclonic epilepsy: a cognitive functional magnetic resonance imaging study. Brain 134(6):1710-1719

74. Wolf $P$, Yacubian EM, Avanzini G, Sander T et al (2015) Juvenile myoclonic epilepsy: a system disorder of the brain. Epilepsy Res 114:2-12. https://doi.org/10.1016/j.eplepsyres.2015

75. Loiseau P, Cohadon F, Cohadon S (1966) Le petit mal qui guérit, guérit rapidement. J Med Lyon 47(108):1557-1559

76. Morse E, Giblin K, Chung MH, Dohle C et al (2019) Historical 1102trend toward improved long-term outcome in childhood absence epilepsy. Epilepsy Res 152:7-10

77. von Podewills F, Lapps S, Wang I, Hartmann U et al (2014) Natural course and prediction of spontaneous seizure remission in idiopathic generalized epilepsy: 7-27 years of follow-up. Epilepsy Res 108(7):1221-1227

78. Gomez-Ilbanez A, McLachlan R, Mirsattari S, Diosy D, Burneo J (2017) Prognostic factors in patients with refractory idiopathic generalized epilepsy. Epilepsy Res 130:69-73

79. Capovilla G, Rubboli G, Beccaria F, Lorenzetti ME et al (2001) A clinical spectrum of the myoclonic manifestations associated with typical absences in childhood absence epilepsy. Performed a videopolygraphic study. Epileptic Disord 3(2):57-62

80. Trinka E, Baumgartner S, Unterberger I, Unterrainer J et al (2004) Long-term prognosis for childhood and juvenile absence epilepsy. J Neurol 251:1235-1241

81. Holtkamp M, Janz D, Kirschbaum E, Kowski A (2018) Absence epilepsy beyond adolescence: an outcome analysis after 45 years of follow up. JNeurol Neurosurg Psychiatry 89(6):603-610

82. Callenbach PM, Bouma PA, Geerts AT, Arts WF et al (2009) Long term outcome of childhood absence epilepsy: Dutch study of epilepsy in childhood. Epilepsy Res 83:249-256. https://doi.org/10.1016/ j.eplepsyres.2008.11.011

83. Kessler SK, Shinnar S, Cnaan A, Dlugos Detal (2017) Pretreatment seizure semiology in childhood absence epilepsy. Neurology 89(7):673-679

84. Grosso S, Galimberti D, Vezzosi P, Farnetani M et al (2005) Childhood absence epilepsy: evolution and prognostic factors. Epilepsia 46:1796-1801

85. Höfler J, Unterberger I, Dobesberger J, Kuchuhkidze $\mathrm{G}$ et al (2014) Seizure outcome in 175 patients with juvenile myoclonic epilepsy-a long-term observational study. Epilepsy Res 110:1817-1824

86. Oh A, Kim H (2020) AED treatment in JME:a population-based study. Neurology 94:315-319

87. Kitazawa J, Kazutaka J, Kakisaka Y, Fujikawa M et al (2018) Predictive factors of higher drug load for seizure freedom in IGE. Epilepsy Res 144:20-40

88. Caplan R, Siddarth P, Stahl L, Lanphier E et al (2008) Childhood absence epilepsy: behavioral, cognitive, and linguistic comorbidities. Epilepsia 49(11):1838-1846

\section{Anfälle mit generalisierten Absencen: Wo stehen wir heute?}

„Generalisierte“ Absencen werden unter den Gesichtspunkten verschiedener Konzepte diskutiert. Im Laufe der Zeit wird unter Berücksichtigung neuer Erkenntnisse die strikte Dichotomie generalisiert vs. fokal hinterfragt, die nach Auffassung der Autoren in mancher Hinsicht kontraproduktiv für die Entwicklung neuer Ideen und Behandlungsansätze ist. Daten von Semiologie, strukturellen und funktionellen Untersuchungen mit quantitativer Elektroenzephalographie (EEG), Video-EEG-Monitoring, Magnetenzephalographie, Magnetresonanztomographie und Positronenemissionstomographie sowie Neuropathologie sprechen für ein nosologisches Spektrum von vorherrschenden fokalen zu generalisierten anfallsgenerierenden Mechanismen. Die Bezeichnungen "fokal“ und "generalisiert" stellen für Anfälle Abstraktionen und Idealisierungen, jedoch keine ontologischen Entitäten dar. Die neue Terminologie und Klassifikation der International League Against Epilepsy (ILAE, 2017) ermöglicht und begünstigt - trotz ihrer großen Verdienste gleichzeitig ein reduktionistisch-vereinfachendes Denken, welches zwar von einer Perspektive des Nützlichkeitsprinzips her pragmatisch erscheint, aber das Risiko in sich birgt, wissenschaftliche Zukunftsentwicklungen zu behindern. Die Semiologie von der Absence - als paradigmatischer "generalisierter" Anfall - wird in der neuen Klassifikation als „non-motor seizure“ klassifiziert. Eine detaillierte phänomenologische Analyse zeigt jedoch, dass motorische Aktivität bei Absencen ein integraler Bestandteil dieses Anfallstyps ist. Sowohl viele motorische als auch „automatische“ Absence-Symptome können als korrelierende Elemente eines globalen kortikalen Organisationsplans verstanden werden. Entsprechende funktionelle und strukturelle Befunde bildgebender Verfahren und der hochauflösenden Elektrophysiologie verweisen auf fokale Vorgänge bei der Anfallsgeneration sowie eine Kombination fokaler und "generalisierter" Merkmale. Ergebnisse funktioneller Untersuchungen zeigen, dass dem Frontalhirn mit Projektionen zu anderen Hirnregionen eine wichtige Rolle bei "generalisierten“ Absencen zukommen kann. In dieser kritischen Überprüfung werden sowohl die Entwicklung pathophysiologischer Konzepte in verschiedenen Dekaden als auch neue innovative Forschungsansätze für Diagnose und Therapie reflektiert.

Schlüsselwörter

Video-EEG · Frontallappe · Gestalt · Pathophysiologie · Behandlung

89. Glauser T, Cnaan A, Shinnar S, Hirtz D et al (2010) Ethosuximide, valproic acid, and lamotrigine in childhood epilepsy. NEngl J Med 362(9):790-799

90. Tomson T, Marson A, Boon P, Canevini MP et al (2015) Valproate in the treatment of epilepsy in girls and women of childbearing potential. Epilepsia 56(7):1006-1019

91. Mostacci B, Ranzato F, Guliano L, La Neve L et al (2021) Alternatives to valproate in girls and women of childbearing age potential with idiopathic generalized epilepsies:state of the art and guidance for the clinician proposed by the epilepsy and gender commission of the Italien league against epilepsy. Seizure 85:26-38

92. French JA, White HS, Klitgaard H, Holmes GL et al (2013) Development of new treatment approaches for epilepsy: unmet needs and opportunities. Epilepsia 54(4):3-12. https://doi. org/10.1111/epi.12294

93. Korff C, Brunklaus A, Zuberi S (2015) Epileptic activity is a surrogate for an underlying etiology and stopping the activity has a limited impact on developmental outcome. Epilepsia 56(10):1477-1481
94. Chowdhury F, Woldman W, Fitzgerald Tet al (2014) Revealing a brain network endophenotype in families with IGE. PLoSONE 9:e110136

95. Wandschneider B, Centano M, Vollmar C et al (2014) Motor coactivation in siblings of patients with juvenile myoclonic epilepsy:an imaging endophenotype? Brain 137:2469-2479

96. van Mierlo P, Höller Y, Focke NK, Vulliemoz S (2019) Network perspectives on epilepsy using EEG/MEG source connectivity. Front Neurol 10:721

97. Höller Y, Nardone R (2021) Quantitative EEG biomarkers for epilepsy and their relation to chemical biomarkers. Adv Clin Chem 102:271-336 (Erratum in: CNSDrugs 33(3):299)

98. Kandokor I, Toth M, Wackermann M, Gymesi C et al (2005) Distribution of spatial complexity and ist change after chronic valproate therapy. Brain Topogr 18:115-123

99. Szaflarski JP, Kay B, Gotman J, Michael Det al (2013) Relationship between the localization of the generalized spike and wave discharges generators and the response to valproate. Epilepsia 3(54):471-480

100. Yeom JS, Kim YS, Lee JH, Jung S, Kwon OY (2015) Temporal current-source of spikes suggests initial 
15 treatment failurein childhood absence epilepsy. Seizure 31:88-93

101. Höller Y, Helmstaedter C, Lehnertz K (2018) Quantitative pharmaco-electroencephalography in Antiepileptic drug research. CNS Drugs 32(9):839-84892

102. Stirling RE, Maturana MI, Karoly PJ, Nurse ES (2021) Seizure forecasting using a novel sub-scalp ultralong term EEG monitoring system. Front Neurol 12:713794

103. Stefan H, Burr W, Fichsel H, Fröscher W, Penin H (1984) Intensive follow-up monitoring in patients with once daily evening administration of sodium valproate. Epilepsia 25:152-160

104. Stefan H, Wang Y, Pauli E, Schmidt B (2004) A new approach in anti-epileptic drug evaluation. Eur J Neurol 11(7):467-473

105. Karoly PJ, Freestone DR, Eden D, Stirling RE et al (2021) Epileptic seizure cycles: six common clinical misconceptions. Front Neurol 12:720328

106. Kostov H, Larsson PG, Røste GK (2007) Is vagus nerve stimulation a treatment option for patientswith drug-resistantidiopathicgeneralized epilepsy? Acta Neurol Scand Suppl 187:55-58

107. Franzoni E, Gentile V, Brunetto D, Cecconi I et al (2010) VNS in drug resistant epilepsy. Preliminary report on a small group of patients. Ital Paediadr J 36:30

108. Araya R, Greiner H, Lewis A, Mangano F (2013) Vagus nerve stimulation for medically refractory absence epilepsy. Seizure 222:224

109. Paz J, Huguenrad J (2015) Microcircuits and their interactions in epilepsy: is the focus out of focus? Nat Neurosci 18(3):351-359

110. Korff C, Nordli D (2006) Epilepsy syndromes undetermined wether focal or generalized. Epilepsy Res 70(1):105-109

\section{R. Thorbecke, P. Brodisch, M.P. Lux \\ Sozialarbeit bei Epilepsie}

Beiträge und Materialien der 15. Fachtagung vom 27. bis 29. September 2018 in Hoffmanns Höfe, Frankfurt am Main

\section{Bielefeld: Bethel-Verlag 2020, 179 S., (ISBN: 978-3-935972-60-4), Broschiert 12,80 EUR}

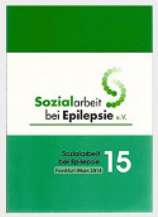

Ende der 1980erJahre entstand durch Initiative von Dieter Janz (19202016) und Gisela Schüler (1928-2013) ein 1998 in "Sozialarbeit bei Epilepsie e.V." übergegangener Arbeitskreis für soziale Fragen bei Epilepsie, der seitdem - u.a. mit Unterstützung der Stiftung Michael - alle zwei Jahre Fachtagungen durchführt und damit ein Forum für die Fort- und Weiterbildung und den fachlichen Austausch anbietet. Aus den Vorträgen und Workshops entsteht jeweils eine Materialiensammlung in Form eines Tagungsbandes.

Der vorliegende Band hat das Rahmenthema „Perspektiven in der Beratung bei Epilepsie" und beruht auf der 15. Fachtagung im September 2018 in den Hoffmanns Höfen in Frankfurt am Main. In ihrem Vorwort schreiben die drei Herausgeber, dass es zunächst um rechtliche und ökonomische Aspekte der Beratungstätigkeit geht, dann um methodische Ansätze inklusive der Schulung von Patienten mit dem Ziel der Befähigung, in der ärztlichen Sprechstunde ihre Fragen einzubringen und Antworten darauf zu erhalten.

Nach Grußworten folgen jedoch zunächst ein sehr gelungener Beitrag der Neuropädiaterin Susanne Rinnert über den Frankfurter Psychiater, Lyriker und Kinderbuchautor Heinrich Hoffmann (1809-1894), Gründer einer Armenklinik und Anatomiedozent am Senckenbergischen Institut in Frankfurt mit später Hinwendung zur Psychiatrie, der 1851-88 Direktor der Städtischen Nervenheilanstalt („,Anstalt für Irre und Epileptische" als Nachfolgeeinrichtung der bereits 1819 gegründeten „Anstalt für Epileptische“) in Frankfurt war und dort fortschrittliche Behandlungsmethoden einführte. Am bekanntesten wurde er allerdings als Autor des "Struwwelpeter" und anderer, ebenfalls zunächst für seine eigenen Kinder gedachter Bilderbücher inkl. „Hanns Guck-in-die-Luft” (wahrscheinlich Kind mit Pyknolepsie) oder "Der Zappelphilipp" (wahrscheinlich Kind mit Aufmerksamkeitsdefizit-HyperaktivitätsSyndrom).

Darauf folgen zwei Beiträge über Epilepsien im höheren Lebensalter, von denen derjenige von Theodor May über die Lebensqualität hervorzuheben ist. Rupprecht Thorbecke und Ralf François haben sehr gute Beiträge über private Versicherungen, Haftungsfragen und das Erstreiten von Leistungen mit Klienten beigesteuert. Der Teil "Methodisches Handeln" besteht aus einem Potpourri von Beiträgen vom "Therapeutischen Schreiben" über "Systemische, lösungsorientierte Beratung" und das Patientenschulungsprogramm KOKOS zur Gesprächsführung mit dem Arzt. Abschließend werden die Ergebnisse von Workshops vorgestellt und es wird über den Aufbau einer Epilepsieberatungsstelle für Litauen berichtet.

Insgesamt aber ein weiterer interessanter Band aus einer traditionellen, nicht nur für Sozialarbeiter und in der Sozialberatung Tätige gedachten Reihe. Ich rate dem Verein „Sozialarbeit bei Epilepsie e.V." jedoch zu einem Verlagswechsel, nicht nur weil die Aktivitäten des Bethel-Verlages außerhalb Bethels weitgehend unbekannt sind (ich habe erst Ende 2021 mehr oder weniger zufällig von dem "schon“ 2020 erschienenen Band erfahren), sondern auch weil die Aufmachung und Gestaltung optimierungsfähig ist. Dies wird auch daran deutlich, dass offenbar vom Vorgängerband übernommene Fehldrucke "Kork 2016" auf dem Titel und Buchrücken durch Aufkleber "Frankfurt/Main 2018" korrigiert werden mussten. Es fehlen auch ein Stich- oder Sachwortverzeichnis und die Adress- und Kontaktangaben der Autorinnen und Autoren.

Günter Krämer, Zürich 